\title{
Exclamative Clauses at the Syntax-Semantics Interface ${ }^{*}$
}

\author{
Raffaella Zanuttini \& Paul Portner \\ Georgetown University \\ zanuttir@georgetown.edu portnerp@georgetown.edu
}

\begin{abstract}
Exclamative clauses exhibit a structural diversity which raises the question of whether they form a clause type in the sense of Sadock \& Zwicky (1985). Based on data from English, Italian, and Paduan, we argue that the class of exclamatives is syntactically characterizable in terms of a pair of abstract syntactic properties. Moreover, we propose that these properties encode two components of meaning which uniquely define the semantics and pragmatics of exclamatives. Overall, our paper is a contribution to the study of the syntax/semantics interface and offers a new perspective on the notion of clause type.
\end{abstract}

\section{Exclamatives and the notion of Clause Type}

Sadock and Zwicky (1985) define clause types as a pairing of grammatical form and conversational use. ${ }^{1}$ In this paper we discuss exclamatives within the context of this notion of clause type. We argue that exclamatives are not a purely semantic or pragmatic category expressed by a variety of unrelated syntactic forms; rather, the diverse realizations of exclamatives all share certain syntactic characteristics. These represent the defining semantic properties of this clause type. Thus, ours is a study of the syntax/semantic interface and its application to the study of exclamatives, and to the notion of clause types more generally.

The syntactic part of our claim is both interesting and difficult because of the diversity of forms which are plausibly to be categorized as exclamatives. Consider, for example:

(1) a. What a nice guy he is!

b. The things he says!

\footnotetext{
We have benefited from discussion accompanying presentations of this work at Georgetown and Yale Universities, and the University of Padova. We are also grateful to the audiences at the Workshop on 'Minimal Elements of Linguistic Variation' in Paris, the Workshop on 'Spoken and Written Texts' at the Univeristy of Texas at Austin, the Going Romance conference at the University of Utrecht and ZAS in Berlin. In particular, we would like to thank Héctor Campos, Ralph Fasold, Elena Herburger, Roumi Izvorsky, Cecilia Poletto, Manuela Ambar, Hans Obenauer, Manfred Krifka, Larry Horn, Bob Frank, and the participants in our graduate seminar on clause types. We would like to extend our special thanks to Paola Benincà, both for providing all of the judgments and for cxtensive discussion of our ideas. This research was supported in part by a Georgetown University Graduate School summer grant.

l More precisely, the set of clause types within a language forms a closed system in that:

1. 'There are sets of corresponding sentences, the members of which differ only in belonging to different types.'

2. 'The types are mutually exclusive, no sentence being simultaneously of two different types' (Sadock \& Zwicky 1985: 158).
} 
(2)
a. Che caro che è!
(Italian)
what expensive that is
'How expensive it is!'
b. Che libro ha comprato Gianni?
what book has bought Gianni
'What a book Gianni bought!'

In (1)a, we have what appears to be a WH movement structure, similarly to an interrogative but without subject-auxiliary inversion. Example (1)b appears to have the structure of a noun phrase which includes a relative clause. Example (2)a, from Italian, is like (1)a in that it involves a WH constituent and no inversion, but contains an overt complementizer; it contrasts with (2)b, which also shows the WH constituent but lacks the complementizer. It is natural to wonder whether these examples have anything syntactic in common.

Given the diversity in (1)-(2), it's not possible to identify a single construction to be labeled 'exclamative'. ${ }^{2}$ We will argue, though, that all of these forms do share certain abstract syntactic properties, and that having these properties is sufficient to identify a sentence as an exclamative. As we will see, these properties are rooted in their connection to the semantics of the clause type. More specifically, they encode the essential semantic components which together yield the meaning of an exclamative. Since these properties may be present in a variety of syntactic forms, they do not yield a set of structures which are syntactically similar in any immediately obvious way. Hence, exclamatives are a category which can only receive a natural characterization at the interface.

This overall picture is quite simple in the abstract, but at the practical level it requires a great deal of detailed work on the syntax and semantics of exclamatives. In both of these areas, we build on some existing work, though compared to other types like interrogatives and declaratives, there is relatively little available. The fundamental idea we will pursue is that there are two syntactic components necessary to make a clause an exclamative. These encode the two key semantic properties of exclamatives:

1. Exclamatives are factive. This is represented in the syntax by an abstract morpheme FACT which brings about a CP-recursion structure (cf. Watanabe 1993).

2. Exclamatives denote a set of alternative propositions, similarly to interrogatives. This is represented by a WH operator-variable structure parallel to that of questions.

In section 4 we will see how these two semantic properties combine to give the intuitive interpretation of exclamation; in section 5 we will see how the two syntactic components which encode them allow an account of the diversity of structures in (1)-

\footnotetext{
2 In this respect, we agree with Michaelis \& Lambrecht (1996). Their approach to this issue, within a construction grammar framework, is to relate individual constructions like those in (1) using an inheritance hierarchy. In this way, the various exclamative sentences can derive their common properties from an 'Abstract Exclamative Construction' while not sharing any structural features in common. Our analysis differs from theirs in that we argue that all exclamatives do in fact share certain defining syntactic properties, and that these properties are essential to their compositional interpretation as exclamatives.
} 
(2). The properties of WH operators in exclamatives are in some cases different from those in interrogatives, and we will explore the differences in some detail in section 6.

A prerequisite for our project is an ability to determine whether a given clause is an exclamative. This is not a trivial task, since other clause types may express a similar pragmatic function, as in (3).
a. He's so cute!
(Declarative)
b. Isn't he the cutest thing! (Interrogative)

Of course this is not a difficulty which is restricted to the study of exclamatives; there are declaratives which function to request information, interrogatives which give an order, and so forth. Unlike with these latter cases, however, there does not appear to be an implicit consensus in the syntax/semantics community as to precisely which sentences count as members of the exclamative clause type. Perhaps this is simply because they have been studied less. Whatever the reason may be, our first task will be to establish some explicit criteria which allow us to determine whether a given clause is an exclamative. We'll undertake this in section 3.

As the last paragraph makes clear, we do not label just any clause which can be used to 'exclaim', in the intuitive sense, an exclamative, just as we would not call Could you come in at 9:00 tomorrow? an imperative simply because it can convey an order. In other words, we distinguish the illocutionary force of a clause from its grammatically encoded function. The illocutionary force of a sentence, as defined by e.g. Searle (1965), incorporates the Gricean analysis of meaning as intentional: 'In speaking a language I attempt to communicate things to my hearer by means of getting him to recognize my intention to communicate just those things' (Searle 1965: 258). A sentence would thus have the illocutionary force of ordering if and only if the speaker intends to impose an obligation by getting the hearer to recognize this intention. According to such a definition, since someone saying Could you come in at 9:00? may have the relevant intention, the sentence would in such cases have the illocutionary force of ordering. But this shouldn't lead to the conclusion that it is an imperative. Crucially its form is that conventionally associated with the force of asking. We label the force conventionally associated with a sentence's form its sentential force, following Chierchia \& McConnell-Ginet (1990). In some cases, such as our example, a sentence whose sentential force is that of asking may have the illocutionary force of ordering. ${ }^{3}$

Likewise with exclamatives, we need to distinguish illocutionary force from sentential force. While members of various clause types may be associated with the illocutionary force of exclaiming, only members of the exclamative clause type are conventionally associated with this sentential force. Certain structures have traditionally been seen as clear examples of this clause type, for example:

$$
\begin{aligned}
& \text { a. What a nice guy he is! (cf. *What a nice guy is he?) } \\
& \text { b. How very tall she is! (cf. *How very tall is she?) }
\end{aligned}
$$

\footnotetext{
It isn't clear whether this kind of example should be seen as having the illocutionary force of asking in addition to that of ordering. While interesting, this issue doesn't affect the point that it is necessary to distinguish the grammatically encoded force from other types of force.
} 
Both of these have an initial WH constituent, but they differ from interrogatives in that they cannot occur with subject-auxiliary inversion. In addition, their WH phrase contains an extra element not possible in interrogatives, $a$ in (4)a and very in (4)b. Despite the presence of such clear cases, the criteria developed in section 3 will prove useful for two reasons: First, they will help us to decide the status of examples like (3)a and $(3) b$ in which the illocutionary force is not equivalent to the sentential force; and second, they will reveal some of the important properties of exclamatives which any theory of this clause type must explain.

Returning to the broader question of how the concept of clause type fits into grammatical theory, exclamatives provide a good place to begin the study of this issue. They are less well-studied than the other types of declarative, interrogative, and imperative. Moreover, their many similarities to interrogatives may make it easier to see precisely which aspects of structure are relevant to distinguishing one clause type from another. And finally, the diversity of structures which appear to exemplify this type, as in (1)-(2), poses a particular challenge for the idea that there can be a useful theory of the grammar of clause types at all. Hence, in addition to being of interest for what it can show us about the nature of exclamatives in particular, this paper also works towards the goal of understanding clause type systems more generally.

\section{Previous approaches to the syntax of force}

Before we examine in detail the nature of exclamatives, we will consider some of the ideas present in the literature concerning the nature of clause typing. One prominent idea is that a force-indicating feature or operator is central to the analysis of individual clause types. Thus, for example, we have imperative force features and question operators used to motivate movement in these types. As we suggested in the introduction, however, we will not pursue this approach. For one thing, such an element does not seem helpful in accounting for the diversity of structures found among exclamatives. In particular, it is hard to see how such a morpheme would let us unify clausal and nominal exclamatives, as in (1)a-(1)b; even the diversity within clausal exclamatives seems too much for a single force feature to account for (Zanuttini \& Portner 2000). Moreover, even for the clause types where the idea has been pursued, there are many problems with the proposal that force is syntactically realized in terms of a single element or feature. In this section we will point out these difficulties.

In most cases, a force indicating element has been proposed for the analysis of a particular clause type (almost exclusively imperatives and interrogatives ${ }^{4}$ ). Authors focusing on other issues will at times invoke a force indicating feature for a narrow range of cases. For example, an illocutionary feature has been used to trigger the verbinitial order of non-negative, non-polite-form imperatives in Spanish or Italian (e.g. Rivero 1994a, Rooryck 1992, Graffi 1996). The goals of such papers aren't necessarily to consider the full range of structures which exemplify a particular clause type, and so they are of less relevance to us here. Others make more general claims about at least one clause type; among them are Pollock (1989), Cheng (1991), den Dikken (1992), Platzack and Rosengren (1994), Rivero (1994b), Henry (1995, 1996), Michaelis \& Lambrecht (1996), Rivero \& Terzi (1995), Rizzi (1997), and Han (1998). Of these,

4 Wechsler (1991) is an exception, considering declaratives is some detail as well. 
Platzack \& Rosengren and Han specifically make claims about how clause types are marked in general, not limiting their claims to a particular type.

We begin by outlining some of the proposals which use a force-indicating element in the analysis of imperatives and interrogatives. In general, we find three main points of view concerning the location of the force-indicating element: (i) force is always represented in $\mathrm{C}$; (ii) force is consistently associated with one projection within a given language, but whether this projection is I or C may vary from language to language; and (iii) force is underlyingly represented in $I$, though it may undergo movement to $C$ in some circumstances. Beginning with imperatives, certain Romance and Balkan languages, among them Spanish, Italian, and Modern Greek, have morphological forms particular to positive, non-polite-form imperatives. This is illustrated by the contrast between the imperative and declarative in (5), from Italian. The imperative verb in (5)a is morphologically unique in that it only occurs as a second person form in imperatives (though it can be a third person indicative); it has a unique syntax as well, obligatorily preceding the object clitic le.
a. Telefonale! call.imp-her
(Italian)

Much of the literature on Romance imperatives proposes that the word order in (5)a results from the verb moving to $C$. The trigger for such movement is the presence of some element associated with the force of imperatives.

Preverbal markers of sentential negation are incompatible with imperatives of this kind. A suppletive verbal form (drawn from the indicative, subjunctive, or infinitive paradigms) is used instead. In (6)b from Italian, the verb takes its infinitival form:
a. $\quad *$ Non telefonale!
neg call.imp-her
b. Non telefonarle!
neg call.inf-her
'Don't call her!'

Both Rivero \& Terzi (1995) and Han (1998) utilize the proposed imperative operator in $C$ to account for this incompatibility. Rivero \& Terzi claim that the negative marker, a head which intervenes between I and C, blocks the verb's ability to move to the force indicator. Crucial to this approach is the assumption that the verb and negation cannot form a unit and move together to $\mathrm{C}$. A difficulty is that other constructions within these languages do seem to show the verb forming a unit with negation (e.g. so-called Auxto-Comp constructions, Rizzi 1982). Moreover, in at least one language discussed by Rivero \& Terzi, Serbo-Croatian, the verb can form a unit with negation, as shown by the fact that a preverbal negative marker is compatible with a verb-initial order in imperatives (as well as other clause types). This raises the question of why this option is possible in Serbo-Croatian and not in other languages.

Han responds to these issues by allowing the verb to move to $C$ in all cases. In the presence of a preverbal negative marker, she claims that the resulting structure is 
semantically uninterpretable. Specifically, the following structure is derived (Han 1998: 42):

$$
\left[{ }_{C P}\left[{ }_{C}\left[{ }_{I} N e g I\right]\left[{ }_{C} I m p\right]\right] I P\right]
$$

Following Kayne's (1994) definition of c-command, the negative marker asymmetrically c-commands the verb (within I), and thus takes scope over it. She makes two other crucial assumptions as well: first, that the verb takes over the force-indicating function of the imperative operator, and second that in general a sentence's force cannot be negated or be within the scope of negation (these alternatives are not clearly distinguished). Hence, she concludes that the configuration in (7) is semantically illformed.

Difficulties arise for these approaches when they attempt to extend their ideas to languages which do allow negated imperatives. Rivero \& Terzi discuss the case of Ancient Greek, which lacks a special syntax for imperatives. The only case which gives rise to verb-initial order, for imperatives as well as declaratives, is when this is necessary to provide an enclisis site for second-position clitics. They account for the lack of an inversion operation specific to imperatives by proposing that the feature encoding imperative force is located in I rather than $C$ in this language. Han, in contrast, maintains for languages that allow negated imperatives the idea that force is encoded in C. There are two classes of such languages. On the one hand, French and other languages with post-verbal negative markers can form negative imperatives simply because I to $\mathrm{C}$ movement can take place without movement of the negative marker, which therefore will not take scope over the force indicator. She assumes the not of Do not do that! to be like French pas in this regard. On the other hand, Han assumes that in English examples like Don't do that the negation does move along with the auxiliary to C. However, the resulting configuration differs from that derived for Italian, Spanish, and Modern Greek in that $n$ ' $t$ does not end up c-commanding the force indicator:

$$
\left[{ }_{C P}[C[\mathrm{Neg} I N e g][C \operatorname{Imp}]] I P\right]
$$

Notice that in (8) I is adjoined to negation, and not the other way around as in (7). For this reason, do, which is in I and has taken over the function of the imperative operator, c-commands negation. The resulting scope configuration is interpretable, as negation does not take scope over directive force.

Turning now from imperatives to interrogatives, many authors have accounted for verb-movement in the latter in terms of an element in $\mathrm{C}$ which indicates that the clause is a question. This element has been instantiated as the $\mathrm{Q}$ morpheme or WH feature originating with Katz \& Postal (1964) and Baker (1970) and employed in much subsequent work. This element bears an obvious similarity to the one invoked in the case of imperatives, and so it is tempting to view it as a force-indicating element as well. (Of the works we are aware of, only Han's explicitly postulates a force-indicating element in $\mathrm{C}$ for interrogatives.) A problem with doing this is that this feature is utilized in both main and embedded clauses, and it is not typically assumed that embedded clauses have force. We can think of two possible directions to pursue here. It might be that the Q morpheme or WH feature only counts as a force-indicator in root clauses, and that when selected by a higher predicate it is semantically inert. Alternatively, it could 
be that sentential force is represented in both root and embedded clauses, but in the latter case it is ignored by subsequent semantic computation. ${ }^{5}$

Most discussions of the Q morpheme or WH feature assume it to be located in $\mathrm{C}$. An interesting variant is that of Rizzi (1996). He proposes that in root clauses the WH feature is underlyingly associated with $\mathrm{I}$; it then moves to $\mathrm{C}$ in order to instantiate a configuration of spec-head agreement with an appropriate wh operator in [spec, CP]. Thus, as with imperatives, within the discussion of interrogatives we find both $\mathrm{I}$ and $\mathrm{C}$ considered as the possible locus of force.

In light of this brief summary, we can now see why invoking a force-indicating element has not been able to explain the concept of clause type. A serious with all of the theories we have considered so far is that they are applicable to only a subset of the structures which comprise each type. ${ }^{6}$ This is most clear in the case of imperatives. Recall that the basic facts in Italian, Spanish, and Modern Greek are that the morphological form specific to imperative meaning cannot be negated, as in (6)a, but sentences with imperative meaning in other morphological forms may be. This class includes both the suppletive forms used for negative sentences, as (6)b, and those used to express polite imperatives. Since these types of imperative do not involve verb movement to C, according to Rivero \& Terzi's and Han's assumptions they do not contain the force-indicating element. Despite this, they share the same sentential force as the non-suppletive forms; that is, they are conventionally associated with the force of ordering just as much as so-called 'true imperatives'. Han appears to dispute this and claim that force is not syntactically represented in those suppletive imperatives based on subjunctive or infinitive morphology, suggesting instead that it is indicated 'via inference' (p. 57). Han's idea is that the infinitive/subjunctive operator expresses an irrealis interpretation compatible with directive force, and presumably incompatible with other forces like assertion. This approach seems to con the pragmatic notion of illocutionary force with sentential force. As noted in the Introduction, pragmatic inference may lead any clause type to be interpreted with any illocutionary force, e.g. declarative as a question, etc., but this is an aspect of interpretation beyond the pairing of form and sentential force which defines clause type. An alternative approach to dealing with those imperatives that do not show verb movement would be to suggest that force is represented in both cases, but only triggers overt movement in one (e.g. because it's 'strong' in one case and 'weak' in the other); this is Han's approach to those suppletive imperatives based on indicative morphology. Saying either that force comes 'via inference', or that the syntactic properties of the force-indicator vary from case to case, amounts to abandoning the idea of a uniform representation for sentential force.

\footnotetext{
This possibility would be implausible if we were working with a notion of illocutionary force, but given our narrower concept of sentential force, it is more likely to be workable. In line with the dynamic semantics idea that the meaning of a sentence is context change potential (or CCP, Kamp 1981, Heim 1982, among others), wc might treat a sentential force as giving a sentence a certain kind of CCP. For instance, the force of assertion creates a CCP that updates the common ground, whereas that of an imperative affects the hearer's obligations. The meaning of the force indicator would then be to map any proposition onto the appropriate kind of CCP. For example, the CCP of a declarative sentence expressing proposition $p$ is the function $f$ which maps any context $C$ onto $C$ ' which only differs from $C$ in that $p$ is in the new common ground. The effect of the force indicator can always be 'undone', retrieving from $f$ the underlying propositional content: if $f$ is applied to the empty context, i.c. that with nothing in the common ground, $p$ can be recovered as the sole element of $\mathrm{f}(\mathrm{C})$.

6 Since they do not work with a force indicator, Michaelis \& Lambrecht's (1996) approach is not subject to this criticism.
} 
A similar problem arises in some languages with interrogatives. In Paduan, for example, while positive yes/no questions involve inversion, those negated by the usual marker of sentential negation, no, do not: ${ }^{7}$
a. Vien-lo?
(Paduan)
comes-s.cl
'Is he coming?'
b. $\quad *$ No vien-lo?
neg comes-s.cl
c. Nol vien?
neg-s.cl comes
'Isn't he coming?'

If inversion results from the presence of a force indicating feature in $\mathrm{C}$, the lack of inversion in (9)c would lead one to conclude that there is no such feature. That is, negative questions, like the negative imperatives discussed above, would differ from their non-negative counterparts in lacking the syntactic representation of force. And yet they are just as fully interrogatives as their non-negative counterparts. The alternative of saying the force-indicating feature is strong in positive clauses but weak in negative ones gives up on the idea that the members of a clause type are unified by sharing a single syntactic feature.

The basic problem we are faced with is that the syntactic operation giving rise to verb-initial order does not correlate with the expression of force which defines a clause type. Thus, in the languages under discussion at least, there is no justification for tying the verb's behavior to any feature which encodes force or clause type. It would be simpler to have a single feature triggering all cases of verb movement to $C$. In Italian and Spanish this would bring together positive imperatives and interrogatives, leaving aside their negative counterparts as well as declaratives. ${ }^{8}$

The approach to exclamatives which we will pursue here doesn't rely on a forceindicating feature or operator at all. While it's possible that such an element is present, it is not what shapes the members of the class. Rather, what is shared by all exclamatives is the need to represent in the syntax those two semantic properties mentioned in the introduction: that exclamatives are factive and that they denote a set of alternative propositions. It is worth wondering whether semantic properties other than force could be helpful in solving the problems mentioned above for the analyses of imperatives and interrogatives, but we will not pursue this in the present paper.

7 Paduan is a Romance variety spoken in the Italian city of Padua. As shown by Poriner \& Zanuttini (1996), Paduan no actually has two, syntactically distinct forms. One is the ordinary marker of negation, while the other is a clitic and carries, in addition to negative meaning, a particular scalar implicature described in the reference cited. Here we focus on ordinary negation. In the Paduan data, the gloss s.cl stands for 'subject clitic'.

8 This line of reasoning follows the assumption made by many in the literature that positive interrogatives in Italian and Spanish involve inversion. The matter is subject to debate because of the range of subject positions available in these languages. Paduan presents a more clear casc; the relative order of verb and clitics provides direct evidence for inversion in all positive interrogatives and imperatives. 


\section{Criteria for identifying exclamatives}

In this section we establish a number of criteria for identifying exclamative clauses, drawn from Zanuttini \& Portner (2000) and Portner \& Zanuttini (2000). We identify three properties which distinguish exclamative clauses and show how they give rise to criteria which help us pick out members of this type. The three properties are: factivity, scalar implicature and inability to function in question/answer pairs. At this point our goal is only to establish criteria; we will provide an analysis of each of the properties in section 4.

Like us, Obenauer (1994, section 2.4) also provjdes criteria for determining the class of exclamatives. Concentrating on data from French, he focuses on certain WH phrases, like quelle chance ('what luck') and quel génie ('what genius'), that can only occur in exclamatives.

(10) a. Quelle chance tu as eue! (Obenauer 1994: 364)

what luck you have had

'What luck you've had!'

b. *Quelle chance as-tu eue!

what luck have-you had

'What luck have you had!'

He then takes their syntax to be definitive of the syntax of exclamatives in general. Thus, since these WH phrases disallow inversion and cannot remain in situ, he concludes that if a WH structure is to be classified as an exclamative in this language, it must not involve inversion or WH in situ. This classification appears to accurately pick out the class of WH exclamatives in French. Notice, however, that Obenauer's criteria are purely syntactic, and so they can only be counted on to single out a syntactically relevant class (similarly to Rivero \& Terzi's class of imperatives involving $\mathrm{V}$ to $\mathrm{C}$ movement). This methodology cannot assure us that all sentences with the relevant sentential force get classified as exclamatives. Since the notion of clause type which we investigate in this paper is defined as a pairing of form and sentential force, we need to make sure that the criteria are not too narrow, thus picking out only a syntactically coherent subset of the clause type. In other words we need to make sure that we are not leaving out other types of exclamatives in the same way that some of the literature on imperatives left out those which do not involve verb movement to $\mathrm{C}$.

For these reasons, our criteria for exclamative status will be built on the three semantic properties outlined above. The first property, factivity, was first pointed out by Grimshaw (1979). ${ }^{9}$ The factivity of exclamatives is shown by two facts. First, they can only be embedded under factive predicates, as seen in $(11):^{10,11}$

9 Michaelis \& Lambrecht (1996) incorporate a similar property, 'presupposed open proposition' into their account. Though it is not formally defined, this property is paraphrased in a way that makes it appear equivalent to Grimshaw's notion of factivity.

10 This is not to say that all factives allow exclamative complements. For instance, regret doesn't allow WH complements in general, as pointed out by a reviewer.

11 The effects of factivity are somewhat different in WH complements than in declarative complements, as discussed in Berman (1991). Note also that the non-factive predicate believe has a special factive use in sentences of the form I can't believe ... or You wouldn't believe ..., and as expected in these cases it can have an exclamative complement: I can't believe how very cute he is! 
Second, when they are embedded under a verb like know or realize, in the present tense and with a first person subject, this verb cannot be negated, as seen in (12):

\section{*I don't know/realize how very cute he is.}

Intuitively, the problem with (12) is that denying the speaker's knowledge con with the factive presupposition generated by the exclamative. ${ }^{12}$

The second property, what we refer to as scalar implicature, makes more precise the intuition that exclamatives convey that something is surprising or noteworthy in some way. Exclamatives introduce a conventional scalar implicature to the effect that the proposition they express lies at the extreme end of some contextually given scale. Thus, we take How very cute he is! to express the proposition that he is very cute (in fact, it presupposes it, due to factivity) and to implicate that his degree of cuteness is greater than the alternatives under consideration. This must be a conventional, rather than a conversational, implicature because it is non-defeasible (as seen in (13)a) and detachable (as in (13)b, which shows that the implicature is tied to the sentence's form not its semantic content):

(13) a. ??How very cute he is! - though he's not extremely cute.

b. He's quite cute! - though not extremely cute.

This property explains two facts. The first, pointed out by Elliott (1974), is that exclamatives cannot be embedded under It isn't amazing, though they can be embedded under its positive counterpart:

(14) a. *It isn't amazing how very cute he is!

b. It is amazing how very cute he is!

The second, related property is that (14)a becomes good if it is questioned, whereas (14)b becomes ungrammatical:

(15) a. Isn't it amazing how very cute he is?

b. *Is it amazing how very cute he is?

The intuitive reason why (14)a is unacceptable is that it denies the amazingness of his cuteness, and this amounts to contradicting the scalar implicature. A parallel explanation holds for $(15) \mathrm{b}$, where the interrogative questions the amazingness of his cuteness, thus casting doubt on the implicature. In contrast, (15)a is acceptable because a negative question expects a positive answer, and thus the pragmatics of this sentence supports the implicature of extreme cuteness.

The third property distinguishing exclamatives from interrogatives and declaratives is their inability to function in question/answer pairs. Obviously, interrogatives characteristically serve to ask a question. Exclamatives may not do so.

12 In certain pragmatic circumstances, an exclamative may serve to provide new information. For instance, when I return from sceing my friend's baby for the first time, I may say What a cute baby he is! We can see this case as introducing the proposition that the baby is very cute via accommodation (Lewis 1979), parallel to examples like I didn't know that she had a new baby. 
(16) A: How tall is he?

B: Seven feet.

(17) A: How very tall he is!

B: $\quad$ *Seven feet. / He really is! / Indeed! / No he's not!

The response Seven feet in (16) provides the information requested by A's question; that is, it is an answer. (Theories of the semantics and pragmatics of questions provide a more formal and precise characterization of what it is to be an answer. For our purposes, we may leave the notion at the intuitive level.) In contrast, the same response in (17) is unacceptable when taken as an answer; to the extent that it's acceptable, it indicates agreement with A's presupposition, like He really is! and the other responses given.

Another criterion arising from the fact that exclamatives do not introduce a question into the discourse is their contrast with interrogatives in patterns like the following:

(18) How tall is he? Seven feet or eight feet?

(19) How very tall he is! *Seven feet or eight feet?

In (18), the second phrase serves to narrow the preceding question, indicating that the answer is to be drawn from the set $\{$ seven feet, eight feet $\}$. In this light, it is clear why (19) is unacceptable. The exclamative does not introduce a question, so there's nothing for the follow-up phrase to narrow.

The final criterion for identifying exclamatives is that, unlike declaratives, they cannot be used as answers: ${ }^{13}$

(20) A: How tall is Tony's child?

B: *How very tall he is!

With this set of criteria, we can now determine whether a sentence whose status is unclear should be categorized as an exclamative. We can illustrate with examples (21)(22) below:

(21) a. Who could be cuter than you?

b. Isn't he the cutest thing?

He's so cute!

1.3 Cortain yes/no exclamatives may be exceptions here. Though the English exclamative in (i), pointed out by McCawley (1973), is not clearly a full clause, its Italian counterpart in (ii) is:

(i) A: Is Tony's child tall? B: And how!

(ii) A: E' alto il bambino di Toni?

is tall the child of Tony

B: Eccome se è alto! (Italian)

and-how if is tall

We speculate that the conjunction which introduces B's utterance has something to do with why these are acceptable. Perhaps they conjoin an elliptical answer with the exclamative, as Yes he is - and how! or Yes, and how he's tall!

Another possible exception is the type seen in Boy, is he! or Is he ever! (McCawlcy 1973). We are not certain that these cases are truly exclamatives, however. They may be pronounced with falling intonation, like a declarative and unlike And how! They may be examples of Sadock's (1971) 'Queclaratives', sentences with the form of questions but the pragmatic force of assertion. 
With regard to the rhetorical WH question (21)a, we can see that it may be embedded under a nonfactive predicate $((23) a)$, and under I don't know ((23)b); thus it is not factive. It may be answered $((23) \mathrm{c})$ and it does introduce a question which may be narrowed $((23) \mathrm{d})$, thus patterning with interrogative and not with exclamatives.

(23) a. I wonder who could be cuter than you.

b. I don't know who could be cuter than you.

c. A: Who could be cuter than you?

B: Nobody.

d. Who could be cuter than you? Your brother or your sister? Not even them!

We cannot construct examples with (21)a that allow us to test for the scalar implicature of exclamatives. Who could be cuter than you may not be embedded under amazing at all, and so we cannot attempt to embed it under It isn't amazing... or Is it amazing.... (In general, questions may not be embedded under amazing. Given this, we may use embeddability under amazing as an additional criterion to distinguish exclamatives from interrogatives.)

The rhetorical yes/no question (21)b can be answered, as seen in (24), and thus behaves unlike exclamatives:

$$
\text { A: Isn't he the cutest thing? B: Yes. }
$$

The other criteria are inapplicable, since a yes/no question cannot be embedded without major alteration of its structure. (One is hardly tempted to consider clauses introduced by whether or if as exclamatives, even in cases like It isn't even a question whether he's the cutest thing!) The only evidence available, then, namely the fact that it can be answered, leads us to consider (21)b an interrogative.

Finally, declaratives with so and such like (22) may be embedded under non-factive predicates $((25) \mathrm{a})$ and under I don't know $((25) \mathrm{b})$, thus failing the factivity test. When embedded under amazing, the sentence may be negated $((25) \mathrm{c})$ or questioned $((25) \mathrm{d})$, illustrating it lacks the scalar implicature of exclamatives. Moreover, it may serve as an answer $\left((25)\right.$ e), once again patterning with declaratives and not exclamatives..$^{14}$
a. I think he's so cute.
b. ?I don't KNOW that he's so cute.
c. It isn't amazing that he's so cute.
d. Is it amazing that he's so cute?
e. A: Is he cute? B: He's so cute.

In the rest of this paper, we classify sentences as exclamatives based on these tests, though for reasons of space we will not give the full set of examples.

\footnotetext{
14 The first three examples are natural with contrastive intonation on so, know, and amazing, respectively. Note that $(25) \mathrm{b}$ has the same intonation and interpretation as the sentence with an embedded declarative $I$ don't KNOW that he's 6'5" cited in footnote 24 . We take this as further evidence that it is an embedded declarative.

15 Michaclis \& Lambrecht (1996) consider examples with such and so to be true exclamatives, but they do not have explicit criteria for distinguishing exclamatives from other clause types.
} 


\section{The semantic and pragmatic analysis of exclamatives}

Our goal in this section is to provide a precise characterization of the sentential force of exclamatives. After outlining our proposal in section 4.1, we'll show how it is able to capture the informal, qualitative descriptions of what exclamatives do in terms of notions like 'surprise', 'unexpectedness', 'emotional reaction', and 'extreme quality' (section 4.2). We'll also discuss how it is able to explain the various semantic properties of exclamatives outlined above (section 4.3). Drawing on our own previous work, in this section and those following we'll make extensive use of data from Paduan. The reason for focusing on this language will become more apparent in section 5, where its unique syntactic properties become relevant.

As we discuss their semantic analysis, it is convenient to divide exclamatives in Paduan into two groups. Parallel to the distinction between $\mathrm{WH}$ and yes/no questions, we find both WH and lyes/no" exclamatives:

Che roba che 1 magna! (Paduan)

what stu that he eats

'The things he eats!'

(27) No ga-lo magnà tuto!

neg has-s.cl eaten everything

'He ate everything!'

Example (26) is introduced by a WH constituent, and rates some of the things that he eats as surprising compared to other, more normal food. In contrast, the example in (27) lacks a fronted WH constituent; it compares the true proposition that he ate everything to the alternative that he didn't, rating the former as less likely.

\subsection{Two components of the force of exclamatives}

The analysis we propose has two main components: factivity and widening. ${ }^{16}$ We will discuss how these two aspects of the meaning are syntactically represented in section 5 ; for now, let us use $\mathrm{R}_{\text {fuctivity }}$ to refer to the representation of factivity in the syntax and $\mathrm{R}_{\text {widening }}$ to refer to that of widening. The role of $\mathrm{R}_{\text {factivity }}$ is straightforward. It introduces a presupposition that the propositional content of the exclamative is true. In terms of (28), this informally means that it is presupposed that he eats something.
a. Che roba che 1 magna!
what stu that he eats
'The things he eats!'
b. The things he eats!

As for the contribution of widening, we assume that $R_{\text {widening }}$ has the semantics of a quantificational operator. To see the role of this operator, let us consider the following context. We're discussing what hot peppers some of our friends like to eat. The domain of quantification for $R_{\text {widening }}$, let us call it $\mathrm{Dl}$, is a set of peppers which contains (in increasing order of spiciness): poblano, serrano, jalapeño, and güero. Our friends who

16 This concept of widening is related to that used by Kadmon \& Landman (1993) in the analysis of any. 
like spicy food tend to eat the poblanos, serranos, and occasionally jalapeños. About one of them, we say (28). In this context, the sentence implicates that he eats all types of peppers, not only all those in D1 but also, for example, the habanero, which is so spicy that it often makes people ill. Uttering (28) thus causes the domain of $\mathrm{R}_{\text {widening }}$, $\mathrm{D} 1$, to be expanded to D2, including this additional type. This expansion of the domain is the widening component of meaning of exclamatives. Widening, in this sense, is closely related to Obenauer's (1994, p. 355) description of the meaning of exclamatives: the WH phrase binds a variable for which an appropriate value cannot be found in the contextually given domain. In order to find the appropriate value, one must look outside of the domain. Though Obenauer's semantic ideas are not spelled out in more detail than this, they clearly bear a close intuitive similarity to our own proposal.

The factivity and widening components can be seen as related to one another. ${ }^{17}$ Given that exclamatives are presupposed, certain functions for root occurrences of them are ruled out. Their sentential force cannot be that of assertion, since that would conflict with the presupposition that the information is already known (though they could, via presupposition accommodation, indirectly introduce new information). They cannot be questions, because it would be pointless to ask a question where the answer is presupposed to be known. Finally, they cannot be imperatives because one wouldn't give an order to do something which one knows will be the case anyway. ${ }^{18}$ Assuming that each type of root clause must have some function, another type of function must be available for exclamatives. The role of affecting, in particular widening, the domain is a plausible one for them to have.

Our goal in the rest of this section will be to formalize the contributions of factivity and widening. As discussed in the speech act theory literature (e.g. Austin 1962, Searle 1965), the illocutionary meaning of a sentence is made up of two components, a propositional part and a force. Building on their syntactic similarity to questions, we propose that the propositional part of the meaning of exclamatives is identical to that of questions, while the force will differ. In particular, we'll work with one prominent approach to the semantics of questions, the proposition-set view (Hamblin 1973, Karttunen 1977, Groenendijk \& Stokhof 1984), according to which questions denote sets of propositions. We'll follow Karttunen in particular in treating questions as denoting their set of true answers. (The other proposition-set views could also be used.) Thus, the question What does he eat? might denote a set like \{'he eats poblanos', 'he eats serranos', 'he eats jalapeños'\}. This same set would be the propositional content of (28)a, as given in (29). ${ }^{19}$

(29) $[$ [ che roba che 1 magna! $]]=\{p: p$ is true and $\exists a[p=$ ' $a$ is a pepper and he eats a'] $\}=\{$ 'he eats poblanos', 'he eats serranos', 'he eats jalapeños' $\}$

Now we are able to examine how we can define widening within our approach. To do this, we need to discuss the notion of the domain of quantification for $\mathrm{R}_{\text {widening. }}$ In $\mathrm{WH}$ exclamatives, this is intuitively thought of as the set from which values for the WH phrase may be drawn; in (28), it would be the set of peppers $\mathrm{D}=$ \{poblano, serrano,

17 This point was suggested to us by Manfred Krifka (personal communication).

18 These points are related to the preparatory conditions on speech acts discussed by e.g. Searle (1965).

19 Note that we differ from traditional speech act theory, according to which the propositional part of a sentence's meaning is taken to be a single proposition. We think of it more broadly, as the semantic object in terms of which the sentence's illocutionary force is defined. 
jalapeño, güero\}. The semantics of the clause must then be given in terms of this contextually provided domain of quantification for $\mathrm{R}_{\text {widening }}$ and an ordering on a subset of $\mathrm{D}$; this is represented by a subscript as in $\llbracket S \prod_{\mathrm{D}, \ltimes}$. Given this, we propose that widening consists in the context change in (30):

(30) Widening: For any clause $\mathrm{S}$ marked by $\mathrm{R}_{\text {widening, }}$, widen the initial domain of quantification for $R_{\text {widening }}$, D1, to a new domain, D2, such that

(i) $\quad$ [IS $\rrbracket_{\mathrm{D} 2,<}-\llbracket S \rrbracket_{\mathrm{D} 1,<} \neq \varnothing$ and

$$
\forall x \forall y[(x \in \mathrm{D} 1 \& y \in(\mathrm{D} 2-\mathrm{D} 1)) \rightarrow x \prec y] \text {. }
$$

Here, $\llbracket S \rrbracket_{D 2,<}$ is the set of true propositions of the form 'he eats $x$ ', where $x$ is drawn from the new domain $D 2$, while $\llbracket S \rrbracket_{D 1,<}$ is the corresponding set for the old domain $D 1$. Saying that the difference between these two, II $S \|_{\mathrm{D} 2, \prec}-\mathbb{I} S \rrbracket_{\mathrm{D} 1, \prec}$, must be non-empty amounts to requiring that new things that he eats be added to the domain. In the scenario outlined above, D2 would differ from D1 in containing habaneros, an the sentence would say that he even eats this very spicy pepper. Thus, the analysis can be seen as representing the intuition that (28) says that he eats any kind of pepper, and that if there is any sort he doesn't eat, it's beyond even the widened domain D2 and thus so far out that it's not worth consideration. ${ }^{20}$

Turning to yes/no exclamatives, note that the Paduan example (27) above contains an instance of negation. Before we can discuss how widening applies to this case, let us point out some relevant facts which may be observed in negative yes/no questions. Let's look at the following examples:
a. Did he eat everything?
b. Didn't he eat everything?

With regard to (31)a, the true answer might be either he did or he didn't. Thus, its propositional content is either \{'he ate everything'\} or \{'he didn't eat everything'\}, depending on which is true. In contrast, because $(31) \mathrm{b}$ is a negative question, it is implicated that the true answer should be he did; thus, the propositional content of the question must be \{'he ate everything'\} ${ }^{21}$ Returning now to the yes/no exclamative,

20 One could consider the possibility that the ordering represented by $\prec$ is not part of the explicit content of widening, but rather that (30)(ii) is a pragmatic implicature which results from the simpler (30)(i). A case where this would potentially be problematical is the following: suppose that in the context of (28), the hearer has simply not been thinking of the jicama (a type of root vegetable. Then, one might expect that (28) could be uttered to draw attention to the fact that the set of relevant vegetables must be expanded. But such a use seems impossible, unless the jicama can be construed as extreme on some relevant scale, for example 'unfamiliarity'; it can't be an ordinary vegetable which the hearer has simply failed to consider. This point suggests that part (ii) of (30) is needed. However, there is a possible alternative. Suppose we require that any domain of quantification for Rwidening be $\prec-$ inclusive, in the sense that if $x$ and $y$ are in $D$ and $x \prec z \prec y$, then $z$ is in D. In that case, it would only be possible to widen, as in (30)(i), by adding an element which is extreme on the $\prec$ scale. Thus, (30)(ii) might be unnecessary. We don't take a stand on the choice between these alternative formulations here.

21 If the implicature is false and the hearer answers by canceling it (No, he DIDN'T), we can think of this in two ways. One possibility is that we take the scmantics of a negative yes/no question to be the same as the positive one; then the propositional content of the negative question would be \{'he didn't eat everything' $\}$ in this case. The other possibility is that the negative question has no true answer when its implicature is false; in this instance, its meaning would be the empty set. 
repeated below, its negation plays a similar role to that in the negative yes/no question (31)b:
No ga-lo magnà tuto!
(Paduan)
neg has-s.cl eaten everything
'He ate everything!'

Because of the negation, (32) can be used to conventionally implicate that he ate everything. A situation in which this might be uttered is one where we are talking about a child who rarely eats all of his meal. On a particular occasion, however, he does. The fact that (32) is used in contexts where the child has eaten everything confirms the idea that it is appropriate to think of it as having a meaning analogous to (31)b.

Another thing we have to decide before the definition of widening can be applied to yes/no cases is what the domain of quantification for $\mathrm{R}_{\text {widening }}$ would be. Since there is no WH word, we can't appeal to the set of possible values for the WH word, as we did above. We propose that this type of yes/no exclamative involves widening the domain of events under discussion; that is, we go from talking about 'normal' events of a certain type to considering even exceptional ones. In the case of (32), D1 would be the set of normal eating situations for the child we're talking about. $\mathbf{R}_{\text {widening }}$ would then say to widen D1 to D2 so as to add true propositions to the original proposition-set. Since a yes/no exclamative, like a yes/no question, denotes either a singleton set or the empty set, in order for this to be possible, two conditions must hold: First, the proposition 'he has eaten everything' must be true with respect to D2. And second, this proposition must not be true with respect to D1; that is, we must have added to the domain an unusual case in which he has eaten everything. ${ }^{22}$ Noting the existence of such an unusual case is precisely what (32) does.

Next we turn to a definition of factivity as it applies to exclamatives. Definition (33) says that any proposition which has been added to the denotation of the clause through widening is presupposed to be true:

(33) Factivity: For any clause $S$ marked by $R_{\text {factivity }}$, every $\mathrm{p} \in \llbracket\left[S \|_{\mathrm{D} 2_{,}}-\llbracket\left[S \|_{\mathrm{D} 1, \prec}\right.\right.$ is presupposed to be true.

In the case of (28), the factive presupposition is that he eats this hottest pepper of all, the habanero. In the case of the yes/no exclamatives like (32), recall from the discussion of widening that its denotation with respect to the initial domain D1 is the empty set, while that with respect to the new domain D2 is \{ 'he ate everything'\}. The characterization of factivity in (33) generates a presupposition that this new proposition in $\llbracket S \rrbracket_{D 2, \prec}$ is true; i.e. it's presupposed that he ate everything. Notice as an aside that according to this reasoning the presupposed proposition, 'he ate everything', is not negative, despite the presence of no. In this way, we can account for the description of this case as containing 'expletive negation' (see also Portner \& Zanuttini 2000).

22 The proposal would work equally well if the proposition-set is empty with respect to D1 or if it is $\{$ 'he didn't eat everything' $\}$. In either case, 'he ate everything' will be in $\left[S\left\|_{D 2, \zeta}-\llbracket S\right\|_{D l_{\ldots} \text {. }}\right.$ 


\subsection{Widening and informal descriptions of exclamatives}

With this formal proposal in hand, we turn next to a discussion of how it can capture the intuitions behind various qualitative descriptions of the use of exclamatives. One frequently finds concepts like 'unexpectedness', 'extreme degree' and 'speaker's strong feelings'; for example, Michaelis \& Lambrecht (1996: 239) consider 'scalar extent' and 'assertion of affective stance: expectation contravention' to be definitive properties of all exclamatives. We do not build our analysis on these concepts because they are difficult to make precise and because (as we will see) they do not always seem to be present. Instead, we will show that that these properties, to the extent that they characterize exclamatives accurately, can be derived from our concepts of factivity and widening.

One intuition is that exclamatives convey an unexpected fact. One way to think about this would be to take an example like How tall Muffy is! as saying that it was unexpected that she is tall. This cannot be correct in general, however, given examples like What a delicious dinner you've made! or What a nice house you've got! In these cases, the speaker doesn't mean to imply that he or she didn't expect a good dinner or a nice house. Rather, the speaker implies that Muffy is taller than expected (the dinner is more delicious than expected, the house is nicer than expected). This way of describing the meaning of exclamatives is completely in accord with our approach, since widening the domain amounts to adding possibilities to those in the previously expected range. However, our approach makes clear that exclamatives have a different meaning from declaratives of the form 'It is unexpected that p'. Though exclamatives also convey the sense of unexpectedness, they do so through a different sentential force. That is, while the declarative It is unexpected that she is as tall as she is and the exclamative How tall she is! end up contributing similar information to the conversation, they do so through different routes: the former through assertion and the latter through widening.

Another way we could describe the meaning and function of exclamatives is by saying that they mark the fact that an entity has some property to an extreme degree (cf. among others Milner 1978, Gèrard 1980). For example, How tall Muffy is! says that Muffy has the property of tallness to a very high degree. While this is certainly correct, it cannot be a complete description since it doesn't explain how the exclamative differs from declaratives like Muffy is very/quite/extremely tall. Our analysis in terms of widening can account for the intuition behind descriptions in terms of 'extreme degree'. With a scalar word like an adjective as the head of the exclamative's WH phrase, the domain of quantification for $\mathrm{R}_{\text {widening }}$ is a set of heights. These heights are organized into a scale, and a domain will naturally be taken as a continuous subpart of the scale, in that if 5' $10^{\prime \prime}$ and 6' are in domain of quantification, 5' $11^{\prime \prime}$ will naturally be as well. Saying that the force of exclamatives involves widening the domain means that the subpart of the scale considered relevant for the case at hand must be extended. This will result in the inclusion of new heights previously considered too great for consideration, one of which will be that of Muffy.

In order to make this reasoning more precise, we'd need to cast it in terms of theories which have been developed to account for the vagueness of scalar terms, comparatives, and the like (e.g. Russell 1905, Cresswell 1976, Hoeksema 1983, von Stechow 1984, Rullmann 1995, Kennedy 1997). In particular, the semantics must be framed in terms of degrees (e.g. of tallness) rather than simple quantities (like heights). Simply talking in terms of the latter wouldn't allow us to explain why extensions of the domain must be in a certain direction (in the case at hand, towards greater rather than lesser heights). We will leave working this out further to future research. 
A final way one might try to describe the meaning of exclamatives, in particular in contrast to declaratives, is by saying that they express the speaker's strong feeling towards what is being said. As it stands, this characterization is too vague to tell us much about the function of exclamatives; after all, it doesn't tell us much about what exclamatives do to simply know that one who says How tall Muffy is! has some feeling towards this fact. There are various ways in which we might try to make this intuition more precise. One possibility is to frame the contribution of exclamatives as conveying an emotional reaction of some sort. Thus, How cute Shelby is! can be seen as expressing adoration and What a vicious dog I met on my bike ride! as expressing fear. The sense that emotion is involved in these cases arises from the particular lexical items, and the scales they introduce, along with the force of widening. If Shelby is cute to a degree beyond what was contemplated before, this is naturally seen as the cause of adoration; likewise, if the dog the speaker met is vicious beyond what we had thought possible, it is plausible to conclude that it caused fear in the speaker. Furthermore, there are cases in which it's not so clear that any emotional reaction is being expressed by an exclamative: How tall she is! or What a cool day it was yesterday in New Delhi! Of course these may be seen as conveying emotion, though in many contexts it seems more relevant to say they simply indicate something surprising. But at this point, our concept of widening is able to provide a more formal characterization of the same idea. With the example What a cool day it was yesterday in New Delhi!, widening means that the temperature is below what we had considered as a relevant possibility before; learning that one's expectations are not met is precisely what gives rise to a feeling of surprise. However, this is the kind of case which very clearly need not generate an emotional reaction in the ordinary sense (for instance, if we take the exclamative as an offhand remark made over the morning paper's weather section).

To sum up, we have suggested that our notion of widening can account for various informal ways in which one can describe the function of exclamatives. The primary advantages of our approach are (i) that it is more precise, and (ii) that it makes clear the difference in force between exclamatives and declaratives like It is surprising that... which assert closely related content.

\subsection{Returning to the tests for exclamative status}

Next we will show how our formal analysis of the meaning of exclamatives is able to explain the data underlying the various tests for exclamative status introduced in section 3. Recall that the tests fell into three categories: factivity, scalar implicature, and question-answer relations. We will look at each in turn.

\subsubsection{Factivity}

The reason our analysis is able to account for the factivity facts is simple: we have directly incorporated a factivity component into the semantics (see (33)). One effect of factivity is that exclamatives are incompatible with non-factive predicates, as was seen in (11). This follows from the presuppositional status of exclamatives, along with the point, noted by Grimshaw (1979), that non-factive predicates are incompatible with factive complements in general. That is, they are not merely non-factive, they are antifactive. The following data makes this point ((34)a is from Grimshaw 1979; see also Kiparsky \& Kiparsky 1970): 
(34) a. *John proposed the fact that they had gone to the movies.

b. John regretted the fact that they had gone to the movies.

Our factivity principle can also explain the ill-formedness of examples like (12) and (35) below:

$$
\text { *I don't know how very tall Tony is. }
$$

The embedded exclamative is impossible because of an incompatibility between the factive presupposition and the lack of speaker's knowledge asserted by the sentence. To show that this intuition follows within our formal implementation requires a certain amount of detailed work. First, we need to go over both the presupposition and the assertion of (35). We'll begin our discussion by looking at the positive version, (36):

\section{I know how very tall Tony is.}

In order to calculate the factivity presupposition for the embedded exclamative, we must compare its denotation with respect to two domains, D1 and D2, each a set of heights (or more accurately, degrees of tallness). D2 is the actual domain at the time the sentence is used, while D1 is some other, smaller domain salient in the context. In the case of (36), we seem to be comparing Tony's actual height to what would be expected for a man like him. Supposing he is 6' $5^{\prime \prime}$, but that men like him are typically no more than 6 ' tall, the two domains might be as follows: ${ }^{23}$

$$
\begin{array}{ll}
\text { a. } & \mathrm{D} 1=\left\{5^{\prime} 5^{\prime \prime}, 5^{\prime} 6^{\prime \prime}, 5^{\prime} 7^{\prime \prime}, \ldots, 6\right\} \\
\text { b. } & \mathrm{D} 2=\left\{5^{\prime} 5^{\prime \prime}, 5^{\prime} 6^{\prime \prime}, 5^{\prime} 7^{\prime \prime}, \ldots, 6,6^{\prime} 1^{\prime \prime}, \ldots, 6^{\prime} 5^{\prime \prime}\right\}
\end{array}
$$

Given these two domains, it is presupposed via the definition of factivity in (33) that Tony is 6' $5^{\prime \prime}$.

Notice that even in the case of an embedded exclamative like (36), we make use of two domains as part of the calculation of factivity. With root exclamatives, the two domains were those associated with widening. Since we have identified widening as the force of exclamatives, we don't expect it to occur with embedded examples as well (since they lack an independent illocutionary force). So, one might ask, what are these two domains? Looking at example (36), it appears that the two domains stand in the kind of relationship which would be appropriate for widening at the root level. Thus, D1 re the 'expected' values while D2 also contains more extreme values, one of which we know to be the true one. If such a D1 and D2 are not available in the context, the exclamative cannot be used. This would only come about if either of the following conditions were to hold: (i) we didn't have an expected range of values, or (ii) we didn't know what the true value was. But of course a failure in (i) would go against the very raison d'être of exclamatives, while a failure in (ii) would imply that factivity does not hold.

Given this factivity presupposition for the embedded exclamative in (36), we must now consider what the larger structures containing it presuppose. As observed by

\footnotetext{
23. We present the degrees of height under consideration as specific numerical measurements (interpreted as 'at least n', so that all of the measurements in (37)b may be true). Only rarely would this be truly appropriate (e.g. in talking about basketball players), but it's simpler than discussing the example using terms like 'average height', 'a bit taller than average', 'pretty tall', etc.
} 
Karttunen (1973), a sentence of the form V -, where V is an attitude verb like believe, know, claim, hope, etc., presupposes that believes whatever - presupposes. Thus, Mary knows that it stopped raining presupposes that Mary believes that it was raining before. Hence, given the context we have set up, (36) presupposes that the speaker believes that Tony is 6' ${ }^{\prime \prime}$. Example (35) has the same presupposition, since negative sentences inherit the presuppositions of their positive counterparts.

Recall that our goal is to show that this presupposition for (35) is in con with what it asserts. Given that we are treating exclamatives semantically like interrogatives, we can interpret know plus an exclamative in parallel to know plus an indirect question. Continuing to follow Karttunen's (1977) semantics for questions, (38) means that the speaker knows each (true) proposition in the denotation of how tall Tony is.

I know how tall Tony is.

Applied to (36), this means that the speaker knows that Tony is 6'5". The negative counterpart (35) thus asserts that the speaker does not know that Tony is 6' $5^{\prime \prime}$. But this is in con with the presupposition that the speaker believes Tony is $65^{\prime \prime} .^{24}$ This con we claim, is the reason for the ungrammaticality of (35).

\subsubsection{Scalar implicature}

Next we will use our analysis of widening to explain the facts attributed in section 3 to the scalar implicature of exclamatives. These were (14)a and (15)b, repeated below along with their Paduan counterparts:

(39) a. *It isn't amazing how very cute he is.

b. $\quad$ No ze incredibile che belo che el ze.

neg is incredible how cute that s.cl is (Paduan)

(40) a. *Is it amazing how very cute he is?

b. $\quad *$ Ze incredibile che belo che el ze? (Paduan) is incredible how cute that S.cl is

Recall that we explained the ungrammaticality of these examples in terms of an incompatibility between the scalar implicature of the exclamative and the denying or questioning of the predicate amazing. Here we will treat the scalar implicature as an effect of the comparison between two domains, the correlate of widening for embedded exclamatives discussed in section 4.3.1. We will show that this aspect of the meaning of exclamatives is incompatible with negating or questioning amazing. (We will only go over the explanation in detail in the case of negation (39); things work similarly for the question (40).)

24 The only way the assertion and presupposition of (35) could fail to be contradictory would be the odd situation in which the speaker believes Tony is 6'5" (which he is) but lacks the right kind of justification for this belief to be knowledge (and knows his or her juslification to be inadequate). But if one is remarking on one's lack of adequate justification for $p$, it's odd to simultaneously presuppose that one believes $p$. We think this is the source of the ungrammaticality of the sentence even in this kind of context. The sentence which is naturally used to report this type of situation, I don't KNOW that Tony's 6'5", differs in that it doesn't presuppose the speaker's belief that Tony is 6'5", but rather just implicates it. 
In order to make the explanation precise, we need to make a detour into the details of the meaning of amazing. Let us consider some additional data contrasting minimally with (39).

(41) a. It's amazing how cute she is. (embedded Q, no experiencer)

b. It's amazing how very cute she is. (embedded $\mathrm{E}$, no experiencer)

(42) a. I'm amazed at how cute she is. (embedded Q, experiencer subject)

b. I'm amazed at how very cute she is. (embedded $\mathrm{E}$, experiencer subject)

The two examples in (41) lack a thematic subject, like (39), contrasting with the experiencer subject sentences in (42). (41)a and (42)a differ from their (b) counterparts in containing an embedded question, as opposed to an embedded exclamative.

The incompatibility with negation noted in (39) only holds with the experiencer-less construction. Negation is fine when the experiencer subject is present:

I'm not amazed at how very tall she is.

This shows that $I t$ 's amazing ... has a different meaning from I'm amazed at .... We will use the contrast between (41) and (42) to determine what this meaning difference is, with the ultimate goal of seeing precisely what the experiencer-less amazing means and why it is incompatible with negation. The first thing to note is that the two examples (41) a and (41)b are synonymous. We know that the embedded exclamative in (41)b involves a relation between two domains parallel to that which contributes widening at the root level. We also know that questions do not involve widening. Thus, for the two sentences to be synonymous, this comparison of two domains must be coming from somewhere other than the embedded question in (41)a. The only plausible candidate is amazing itself. We thus hypothesize that the meaning of amazing, when it lacks a thematic subject, makes a contribution parallel to that of an embedded exclamative; more precisely, it asserts the existence of two domains D1 and D2, the former the expected range and the latter an extension of this which includes the value presupposed to be true. Given this, negating this version of amazing, as in (37) above, will lead to a contradiction between the presupposition, from the exclamative, and denial, from the negation of amazing, that two such domains exist.

The experiencer sentences with amazed at differ in that they have additional entailments pertaining to the (denotation of the) subject. Thus, the examples in (42) imply that the subject has a specific kind of subjective experience, a feeling of 'marvel'. This aspect of its meaning is over and above the comparison of two domains present in the meaning of the sentences in (41). It is this difference which accounts for the grammaticality of (43). In this case the negation may be taken as denying the subjective experience of marvel, and not the domain comparison, and so it can be compatible with the interpretation of the embedded exclamative. This contrasts with (41), where negation may only be seen as denying that a D1 and D2 of the relevant sort exist.

This way of looking at the meaning of amazed at also explains another fact: when the subject is other than I, examples with an embedded question, (44)a, and those with an embedded exclamative, (44)b, differ in meaning:

(44) a. Linda is amazed at how cute the baby is.

b. Linda is amazed at how very cute the baby is. 
While in both cases an expected and a widened domain are compared, there is a difference in terms of whose expectations are at issue. Example (44)a says that the degree of cuteness exceeds what the subject expected; (44)b implies in addition that the speaker also finds her degree of cuteness exceptional. This difference can be brought out in a situation where the subject's and the speaker's expectations differ. For instance, suppose that Linda does not in general think that babies are cute, whereas the speaker finds each and every baby darling. In such a situation, while the use of (44)b may implicate that the speaker finds the baby's appearance especially worthy of exclamining, (44)a does not. We may explain this difference as follows: In (44)b (as in (42)), both amazed at and the embedded exclamative bring about a comparison of two domains. The expected domain D1 relevant for amazed at re the subject's expectations, while the D1 associated with the embedded exclamative has to do with the speaker's. In this way, with an embedded exclamative both the speaker and the subject must be committed to the situation's being worthy of exclaiming. In contrast, with (44)a only amazed at brings in an expected domain (Linda's); the embedded question does not.

\subsubsection{Question/answer relations}

Finally we return to the facts showing that exclamatives may not be answered and typically may not be used as an answer. The first point follows from the simple fact that the function of exclamatives is not to introduce a set of alternatives into the discourse in the way questions do. Rather, we have proposed that their function is widening the domain. The specifics of our account of widening don't play a role here; the point is simply that the force of exclamatives does not affect the discourse in a way which opens the door for answering.

Exclamatives typically cannot be used as an answer because they are factive (though we noted a possible exception in note 13). In general, a sentence being used as an answer may not presuppose the information which provides the answer, as pointed out by Grimshaw (1979). Thus, (45) is unacceptable because It's odd that... is factive (Grimshaw's example (154), p. 321):

$$
\begin{array}{ll}
\text { A: } & \text { Did Bill leave? } \\
\text { B: } & \text { *It's odd that he did. }
\end{array}
$$

Since exclamatives are factive, we expect them to be impossible as answers.

\subsection{Conclusion}

In this section, we have identified two semantic properties which characterize exclamatives: they are factive and they trigger the operation of widening. These semantic components together can explain all of the data which motivated our criteria, and could capture various informal ways of describing the contribution of exclamatives.

\section{The structure of exclamatives}

We now turn to the 'form' side of the form/meaning pairing which is the basis of the concept of clause type. Our picture of the syntax/semantics interface suggests that a clause should be an exclamative if and only if these two components are structurally represented. In this section, we argue that this is so, looking at data from Paduan, 
English, and Italian. In particular, we propose that widening is tied to the presence of a WH operator. ${ }^{25}$ The widening operation discussed in section 4 requires a set of alternative propositions, and the WH operator provides this set of alternatives in just the same way as it does in an interrogative. In addition, we claim that the factivity of exclamatives is represented by a CP layer of structure. The purpose of this section is to support the idea that factivity is syntactically represented in the CP-domain.

\subsection{CP-recursion: some initial evidence from Paduan}

Paduan provides direct evidence that exclamative clauses contain an extra $\mathrm{CP}$ layer of structure. We will identify three ways in which WH exclamatives and questions in Paduan differ syntactically, ${ }^{26}$ and then show how these differences can be explained by proposing a second layer of $\mathrm{CP}$ for exclamatives. In Section 5.2 we will provide arguments that exclamatives in other languages, in particular Italian and English, have a similar structure.

The first contrast between exclamatives and interrogatives in Paduan is in the linear order of the WH phrase with respect to left-dislocated constituents (cf. Benincà 1996). WH constituents in questions can follow, but cannot precede, left-dislocated elements:
a. A to sorela, che libro vorissi-to regalar-ghe? (Paduan) to your sister, which book want-s.cl give-her
'To your sister, which book would you like to give as a gift?
b. * Che libro, a to sorela, vorissi-to regalar-ghe?
a. To sorela, a chi la ga-li presentà? your sister, to who her have-s.cl introduced 'Your sister, to whom have they introduced her?
b. *A chi, to sorela, ghe la ga-li presentà?

In contrast, complex WH constituents in exclamatives may precede the left-dislocated element: ${ }^{27}$

(48) a. Che bel libro, a to sorela, che i ghe ga regalà! what nice book, to your sister, that s.cl her have given 'What a nice book, to your sister, they gave her as a a gift!'

b. In che bel posto, to fjolo, che te lo ga mandà! in what nice place, your son, that s.cl him have sent 'In what a nice place, your son, you sent him!'

We can summarize Benincà's (1996:41) conclusions about the possible relative orders among left dislocated elements and WH constituents as follows:

25 Based on data from Dutch, Corver (1990, Ch. 5) argues that the WH operator wat ('what') in CP can function to mark a clause as exclamative.

26 The precise characterization of all of the subtypes of exclamative clauses in Paduan is quite complex. See Zanuttini \& Portner (2000) for detailed description.

27 Simple ones may not, nor may WH phrases headed by adjectives or adverbs. We discuss these facts in detail in section 6.1 . 
The pattern of behavior of WH phrases in exclamatives is in this way similar to that of WH phrases in relative clauses, discussed by Rizzi (1997).

The second way in which questions and exclamatives in Paduan differ is with respect to the nature of the element in the $\mathrm{C}$ position. The $\mathrm{WH}$ constituent in an exclamative cooccurs with either the complementizer che or the complex head $[\mathrm{v}$ no $\mathrm{V}]$ (plus associated clitics) in $\mathrm{C}$ :
a. Cossa che 1 magnava!
what that s.cl ate
'What things he ate!'
b. Che libro che te lezi!
what book that s.cl read
'What a book you are reading!'
(51) a. Cossa [no ghe dise-lo]!
what neg him says-s.cl
'What things he's telling him!'
b. Che libro [no lezi-to]!
what book neg read-s.cl
'What a book you are reading!'

In contrast, co-occurrence of the WH phrase and the complementizer che or no+V is never possible in matrix questions:
a. *Cossa che I magnava?
what that s.cl ate
'What did he eat?'
what neg has-s.cl eaten
'What didn't she eat?'
b. *Cossa no ga-la magnà?

A final difference between Paduan WH questions and exclamatives concerns the obligatoriness of movement: overt movement is obligatory in exclamatives but not in questions (Benincà 1996, Gérard 1980, Obenauer 1994, Radford 1982).

We take the similarities we have examined to suggest that questions and exclamatives both involve movement of the WH constituent to a $\mathrm{CP}$ position. At the same time, we take the observed differences to suggest that the requirements that must be satisfied in the two cases are not identical. In particular, we hypothesize that exclamatives involve movement to a position which is structurally higher than the one involved in questions:

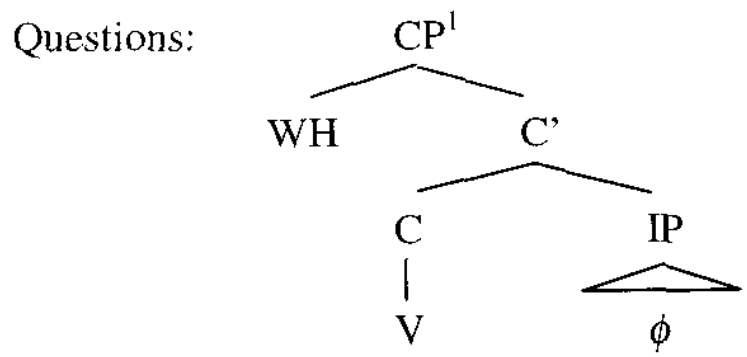


(54)

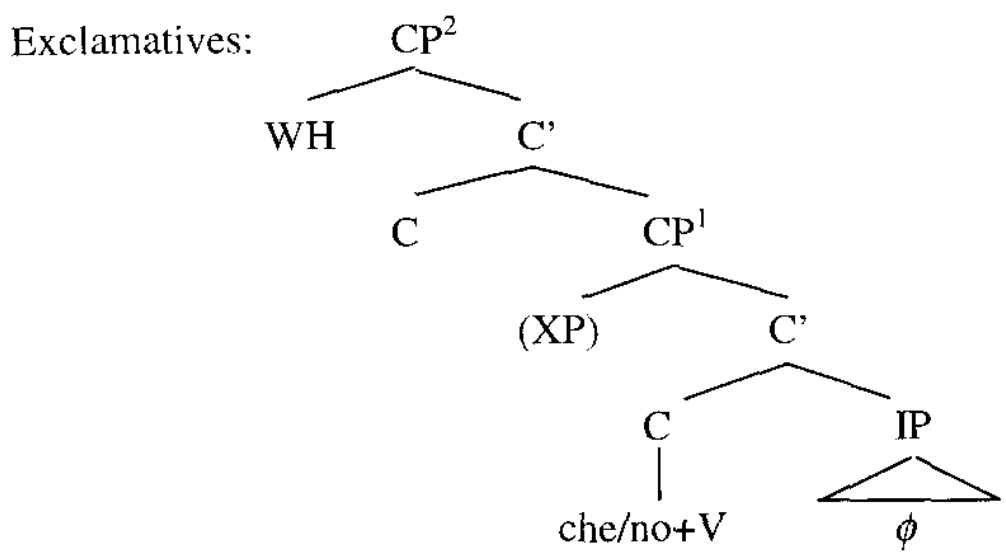

Given these structural analyses of the two clause types, the properties differentiating exclamatives from interrogatives are derived as follows:

- The WH phrase occurs in the higher CP in the syntax, leaving room for another phrase in the spec of the lower CP.

- The lower $\mathrm{C}^{0}$ is always filled, either by che or by no plus the verb; the fact that the WH phrase is in the higher projection allows for the presence of che without a doubly-filled-COMP filter violation. ${ }^{28}$

- The higher specifier of $\mathrm{CP}$ position must be filled, giving rise to the obligatoriness of movement in exclamatives.

We speculate that yes/no exclamatives also use both layers of $\mathrm{CP}$ structure, though we don't have the same kind of direct evidence available with WH exclamatives. In (55) and (56)a, the obligatory boy or ecome can be seen as residing in the higher CP. However, the negative inversion (56)b would have to be seen as containing an abstract operator in this position.

*(Boy) if syntax isn't fun!
a. *(Ecome) se 1 ga pianto! (Paduan) and how if s.cl has cried
'And how she cried so!'
b. No ga-lo magnà tuto!
neg has-s.cl eaten everything
'He's eaten everything!'

We leave a more detailed analysis of yes/no exclamatives to future work.

Besides the empirical arguments concerning Paduan given above, there is another, more theoretical point which supports the idea that exclamatives may involve an extra layer of CP structure. This arises from the factivity of exclamatives. It has been argued by Watanabe (1993) that factive complement clauses involve CP-recursion. Assuming that this is correct, it is plausible to suggest that the factivity of exclamatives is syntactically encoded by the presence of the extra $\mathrm{CP}$ layer (i.e. $\mathrm{CP}^{2}$ in (54) is the $\mathrm{R}_{\text {fuctivity }}$ of section 4.1 ). We will discuss the connection to factivity in more detail in section 5.2. 28 Embedded WH questions may contain che. Thus whatever principle rules out a doubly-filled-COMP
in root interrogatives is not operative in embedded contexts. 
Stepping back for a moment, we'd like to point out for future research the number of connections among the categories of NP, factive complement clause, and exclamative. To begin with, some exclamatives in English have the structure of noun phrases:

a. The things he eats!

b. The things he does to impress his friends!

In addition, others resemble free relatives, as seen in (58):

a. What things he eats! (cf. What things he eats I eat too.)

b. What he does to impress his friends! (cf. What he does to impress his friends bothers me.)

Admittedly there are differences between the ordinary free relative construction and the subtype of exclamatives in (58); for instance, a free relative allows who as its WH word (I like who he likes), but an exclamative doesn't (*Who he likes!). Nevertheless, the overall affinity between exclamatives and NPs in English supports treating the cases in (58) as free relatives in terms of their structure. Rizzi (1997) argues that Italian relatives involve WH movement to a higher projection than interrogatives. Given that the exclamatives in (58) have the structure of free relatives, this supports our contention that exclamatives in general involve multiple layers of structure in the CP-domain. This way of looking at things suggests a link to the analysis of factives more broadly. Factive complement clauses have been argued to involve structure above the basic CP level, and this structure has been identified both as a CP (Watanabe 1993) and as an NP (Kiparsky \& Kiparsky 1970). Furthermore, Koster (1994) mentions that clausal complements of factives in Dutch behave like NPs in that they are obligatorily in pre-verbal position. The overall picture that emerges here is that factives in general, and exclamatives in particular, are expressed with structures containing a CP plus another maximal projection above. This higher projection has been analyzed as an NP or a CP. In the long run we'd like to investigate whether it may indeed be of either category, or whether it has a uniform analysis with the surface properties of one or the other emerging in different languages or contexts.

\subsection{The syntax of factivity}

In the previous section we discussed evidence that exclamatives contain a more articulated CP structure than interrogatives. We will now provide arguments that this extra structure is connected to one of the two semantic properties that characterize exclamatives, namely factivity. In doing so, we build on the work of Watanabe (1993), who argues that factive complement clauses involve CP-recursion. He proposes the following structure for embedded factive declaratives, where FACT represents a 'factive operator':

a. John regrets that he fired Mary. (Watanabe 1993: 527)

b. $\quad \ldots\left[\mathrm{CP}\left[\left[\mathrm{C}\right.\right.\right.$ that ${ }_{\mathrm{i}}\left[\mathrm{CP}\right.$ FACT $\left.\left.\left.\left.\left[\left[\mathrm{C} \mathrm{t}_{\mathrm{i}}\right] \mathrm{IP}\right]\right]\right]\right]\right]$

He presents both empirical and theoretical motivations for such structure. On the empirical side, he uses it to account for the well-known observation that adjunct extraction is more difficult from factive clauses than from non-factive ones; the factive 
operator occupies the specifier of (the lower) CP, thus blocking movement of the adjunct. ${ }^{29}$ On the theoretical side, he adopts the proposal of Authier (1992) that a clause with any type of material in the specifier of its highest CP is typed as a WH-clause. In (59) regret selects a non-WH complement; hence, the top $\mathrm{CP}$ layer of its complement clause must have an empty specifier so as not to be typed as a WH clause. This motivates the presence of an additional CP layer above the one hosting FACT. The derivation indicated in (59)b involves creating this second $\mathrm{CP}$ by raising that . This is necessary to allow FACT to be selected by the higher predicate; the idea is that a configuration in which the two CPs share the same head allows regret to have a selection relation towards both of them.

Watanabe makes a similar proposal for embedded topicalization like (58):

(60) a. John said that this book, Mary should have read. (Watanabe 1993: 524)

b. $\quad \ldots\left[{ }_{C P}\left[\left[_{C}\right.\right.\right.$ that ${ }_{i}\left[\mathrm{CP}\right.$ this book $\left.\left.\left.\left.\left[\left[_{\mathrm{C}} \mathrm{t}_{\mathrm{i}}\right] \mathrm{IP}\right]\right]\right]\right]\right]$

For us, the main relevance of his analysis of embedded topics is that they show overtly that the specifier of the lower CP is occupied. Since FACT and the topic compete for the same position, this predicts that embedded topicalization should be impossible in factive complements. This prediction is borne out in the following examples, as noted by Iatridou \& Kroch (1992) and Watanabe (1993):

(61) a. *John regrets that Mary he fired.

b. *John regrets Mary that he fired. (Watanabe 1993: 528)

While (61)a is certainly better than Watanabe's (61)b, it is nevertheless unacceptable.

Given recent theoretical work on the nature of the CP domain (Rizzi 1997, Benincà 2001, among others), the syntactic analysis of this type of data needs to be revisited. In particular, we now take the CP domain to provide several positions for clause-initial elements, differentiated by their semantic/pragmatic function, and so (61) can't simply be explained in terms of competition for a single specifier position. Moreover, on the empirical side it seems at best partially correct to say that factive complements are incompatible with a clause-initial topic. As pointed out to us by a reviewer, data like the following are acceptable:

(62) Mark didn't understand the first part of your thesis. In fact, he regrets that most of it he was unable to understand.

Assuming that Iatridou \& Kroch and Watanabe's basic intuition is correct, the question is whether a more sophisticated understanding of the structure of $\mathrm{CP}$ allows us to accommodate data like (62) as well.

Without undertaking the whole project of reinterpreting Iatridou \& Kroch and Watanabe's idea in Rizzi-style terms, it does seem to us that the embedded topic in (62) has a special status. It is clearly focused and constrastive with the first part of your thesis. The split-CP framework provides separate positions for contrastive topics (Rizzi's "focalized elements") and neutral topics, and perhaps only the latter are

29 Watanabe also comments on the impossibility of complementizer deletion in factive complements. However, his explanation of this property is presented as a speculative remark and requires additional assumptions not relevant here, so we will not discuss it further. 
in complementary distribution with the factive operator. In any case, what we care about here is the question of whether there is evidence independent of exclamative constructions for the presence of a factive operator in the syntax. The work of Watanabe and Iatridou \& Kroch can still be seen as providing such evidence as long as they have shown an incompatibility between factivity and some particular variety of topical element.

Returning to the analysis of exclamatives, we adopt the idea that factivity is represented by a factive operator in the $\mathrm{CP}$ domain and suggest a more precise representation for (63):
a. Che alto che 1 ze!
what tall that s.cl is
'How tall he is!'
b. [CP che alto [[C $\emptyset][\mathrm{CP}$ FACT [C che] IP $]]]$

In this construction, two specifiers of $\mathrm{CP}$ are needed in order to host both the factive operator and the WH phrase.

A side issue that arises here is how WH-movement of che alto is able to move past the factive operator, given the island effects attributed to this operator by Watanabe. We suggest that FACT does not have the right feature content to count as an intervening potential attractee for WH movement to the higher $\mathrm{CP}$; specifically, it has no WH feature. This way of looking at WH exclamatives still allows an explanation of why extraction is not possible from embedded factives like (59). Movement of a WH phrase to the specifier of the highest embedded CP in (59) would type the clause as WH, and this would be incompatible with the selectional requirements of regret. (In the complement of a non-factive, the Spec of CP will not be filled by FACT; once the WH phrase lands there, the complementizer can raise to prevent the clause from being typed as WH.) Direct movement from the embedded IP to the main clause's specifier of CP is ruled out by whatever forces successive cyclic movement; in Chomsky's (1998) terms, this would be the fact that only the periphery of a phase is visible to subsequent derivation.

We may now see how the structure proposed in (63)b types the clause as an exclamative. In root contexts, the mere presence of the factive operator suffices, as no other clause type is compatible with factivity when unembedded. As mentioned earlier, this is so because it does not make sense to assert, order, or ask about a proposition which is presupposed to be true. In embedded contexts, the structure is rather similar to embedded factive declaratives like (59), but the combination of the WH element and the factive operator distinguishes exclamatives from all other types. On the one hand, while embedded interrogatives would contain a WH feature, they are not compatible with factivity; on the other, embedded declaratives could have the factive operator, but are incompatible with the WH constituent.

We can now turn to how these ideas may be applied to a more precise analysis of nominal exclamatives as in English: $:^{30}$

30 One question that arises at this point is how an nominal structure like (61) could have the clause-like interpretation of a proposition associated with a sentential force. For readers who may be interested, let us sketch how such a reading can be compositionally derived, comparing its derivation with that of an ordinary relative.

In the case of a simple noun phrase containing a relative clause, the IP containing a gap denotes an open proposition (i.e. a proposition relative to an assignment function). The role of the relative 
(64) a. The things he says!

b. $\left[_{D P}\left[\left[_{D}\right.\right.\right.$ the $]\left[{ }_{N P}\right.$ things [ ${ }_{C P}$ WH [[C $\varnothing\left[{ }_{C P}\right.$ FACT [C $\left.\varnothing\right]\left[{ }_{I P}\right.$ he says $\left.\left.\left.\left.\left.\left.\left.]\right]\right]\right]\right]\right]\right]\right]$

The key novel feature here is the presence of multiple layers of CP within the relative clause. In theoretical terms this is again motivated by the need to represent both WH and factivity. It receives empirical motivation from Rizzi's (1997) study of the structure of the $\mathrm{CP}$ domain. He argues that the $\mathrm{CP}$ projection occupied by relative pronouns is structurally the highest in the clause. This leaves the lower projections of the CPdomain open to host other material. For example, drawing on Italian data he provides cases of embedded clitic left-dislocation within a relative clause. The relative pronoun must precede the left-dislocated element il premio Nobel, contrasting with interrogatives where it must follow:

a. Un uomo a cui, il premio Nobel, lo daranno senz'altro. (Italian, Rizzi 1997)

a man to whom the prize Nobel it will-give without-other 'A man to whom they'll undoubtedly give the Nobel Prize'

b. Il premio Nobel, a chi lo daranno? the prize Nobel to who it will-give 'The Nobel Prize, who will they give it to?'

If Rizzi is correct, it is plausible to claim that the relative pronoun in (64) is quite high in the clause, and not in competition with the factive operator for a single structural position. Drawing this together with what we've said about (63), we propose that all exclamatives contain a factive operator in the specifier of a particular CP projection. This factive operator is incompatible with a certain type of topic, but is compatible with certain WH operators and contrastive topics.

To summarize, we have claimed that the syntax of exclamatives is determined by the need to encode the two semantic components which characterize this clause type. They must provide a set of alternative propositions, required by widening, and they must represent factivity. The set of alternative propositions is provided through the presence of a WH operator-variable structure, just as with interrogatives. Factivity is represented by an operator within the CP domain. A phrase is classified as an exclamative at the interface if it has these two syntactic properties.

pronoun is to turn this into a predicate; for example, whom he met would denote the set of entities he met (or the characteristic function thereof). This set is then combined with the head noun by set intersection, so that, for instance, women he met denotes the set of entities $\mathrm{x}$ such that $\mathrm{x}$ is a woman and he met $x$ (or more precisely, its characteristic function). This is an ordinary NP denotation, and can be combined with the determiner without difficulty.

In the case of the exclamative, we would suggest that the relative and head noun do not combine by intersection. Rather, the meaning of the relative pronoun is such that it causes the clause to take the head noun as an argument and yield a sentence meaning. In the case of the women whom he met, he met would continue to denote an open proposition, but the relative pronoun would turn this into a function from $\mathrm{N}$ meanings to sentence meanings. Thus, whom he met would denote $\lambda \mathrm{P}$ [he met some P], and women whom he met would denote the proposition that he met women. Due to the presence of the factive operator, this proposition is presupposed. Finally, according to our principles this proposition is then associated with exclamative force at the DP level. 


\section{The syntax of the WH phrase in exclamatives}

The account we have given so far of the way in which clauses are typed as exclamative is quite simple: they must have a factive operator and a WH phrase. These two elements correspond to the two semantic components which distinguish exclamatives from other clause types. However, as mentioned in the Introduction, exclamative clauses exhibit significant diversity in their structure. This raises the question of whether our simple proposal is too simplistic. We will argue that it is not. Focusing on WH exclamatives, we will see that, amidst all of their diversity, what consistently distinguishes them from other clause types is the presence of the WH phrase and factive operator.

We think that the key to understanding the diversity of exclamative clauses is a detailed understanding of the WH phrases they contain. Not all WH phrases are alike. Some only occur in exclamatives, while others may occur in both exclamatives and interrogatives. A close examination of the internal makeup of the former group reveals that they contain a morpheme not present in the latter. This morpheme has a special relation to the factive operator. As a consequence, this class of WH phrases occupies a position very high in the CP field. WH phrases which may occur in both exclamatives and interrogatives, in contrast, occupy a lower position. This difference in position leads to a number of other structural consequences. In Italian, for example, the WH phrases which only occur in exclamatives differ from the others in that they require the presence of the complementizer che and can be followed by a left-dislocated element.

Our appeal to a number of positions for WH phrases is in accord with a number of other proposals in the literature (e.g., Rizzi 1997 and Benincà to appear). Our study allows us to make a contribution to this approach by pointing out the relevance of some novel data. In addition, because exclamatives are factive, we are able to tie proposals concerning the syntactic representation of factivity to this literature on the positioning of WH phrases. We will attempt to present our findings in a way which is neutral on various issues of detail concerning the structure of the 'left periphery', since the considerations which we bring up add to, rather than modify, the set of arguments that have been put forth.

\subsection{Italian and Paduan}

\subsubsection{Two classes of WH phrases in Italian}

As mentioned above, we may distinguish two groups of WH phrases. One only occurs in exclamatives, while the other may occur in both exclamatives and interrogatives.

1. Some WH phrases that occur in exclamatives do not occur in interrogatives:

(66) a. Che tanti libri che ha comprato!

which many books that has bought

'How very many books s/he bought!'

b. * Che tanti libri ha comprato?

which many books has bought

(67) a. Che alto che é!

which tall that is

'How very tall he is!' 
b. *Che alto é?

which tall is

The WH phrases in (66)-(67) have a number of other properties which also need to be explained. First, they must cooccur with the complementizer che $:^{31}$
a. $\quad *$ Che tanti libri ha comprato!
which many books has bought
b. * ${ }^{*}$ Che alto é!
which tall that is

And second, as mentioned above they allow a left-dislocated constituent to their right:

(69) a. Che tanti libri, a tua sorella, che le hanno regalato!

which many books to your sister that her have given

'How very many books they gave to your sister!'

b. Che bel posto, a Giorgio, che (gli) hanno assegnato! (Benincà to appear)

which nice place, to Giorgio, that him have assigned

'What a good place they assigned to Giorgio!'

2. All WH phrases that occur in interrogatives also occur in exclamatives. For example: $:^{32}$

(70) a. Chi inviterebbe per sembrare importante!

who would-invite for to-seem important

'The people he would invite to seem important!'

b. Chi inviterebbe per sembrare importante?

(71) a. Cosa farebbe per i suoi gli!

what would-do for the his children

'The things he would do for his children!'

b. Cosa farebbe per i suoi gli?
a. Quanto é alto!
how much is tall
'How tall he is!'
b. Quanto é alto?

31 Radford (1997; 101) only reports che+ADV as requiring the complementizer, saying that che+ADJ/PP merely prefers its presence. He doesn't consider che tanti+N. The data in this paper are based on the judgments of the first author. We find the examples with adjectives and adverbs to pattern the same as one another. As Radford notes, however, there appears to be significant variation, perhaps regionally based.

32 Root exclamatives with chi and cosa are most productive with a verb in the conditional, and for some speakers with negation, though Rigamonti (1981:78) reports Che cosa/Cosa/Che mi tocca fare! ('The things I have to do!') and Chi mi tocca incontrare! ('The people I have to meet!'). In this paper we do not focus on these factors. We discuss the role of the negative marker in Portner \& Zanuttini (1996, 2000).

The WH words dove ('where'), come ('how'), and quando ('when') behave like chi ('who') and cosa ('what'). Perché ('why'), like its English counterpart, fails to occur in root exclamatives, but is possible embedded (*Perché l'ha fatto! vs. Sapessi perché l'ha fatto! 'You should hear why he did it!'). 
(73)
a. Quanti/quali
libri ha
comprato!
how many/which
books has
bought
'How very many/what books s/he bought!'
b. Quanti libri ha comprato?

In contrast to those WH phrases that only occur in exclamatives, these do not allow the complementizer:

(74) a. *Chi che inviterebbe per sembrare importante!

who that would-invite for to-seem important

b. * Cosa che farebbe per i suoi figli!

what that would-do for the his children

c. *Quanto che é alto!

how much that is tall

d. ??Quanti/quali libri che ha comprato!

how many/which books that has bought

'How (very) many books s/he bought!'

The judgement concerning (74) d is less than clear. It seems better than chi and cosa, but worse than che alto and che tanti libri in (68).

These WH phrases also disallow a left-dislocated constituent to their right, for example: $:^{33}$

33 There is one WH word which we have not included in our discussion. Come ('how') essentially falls into our second group, but it raises some additional issues which lead us to avoid building on it in what follows. Like WH phrases in our second group, it may occur in both exclamatives and interrogatives and disallows che and left dislocation to its right, as seen in (i):

(ia) Come (*che) é stata brava! (cf. Radford 1997: 102)

how (that) is been good

'How good she was!'

(ib) Come é stata? (Answer: Brava.)

how is been

'How was she?'

(iia) Come (*che) canta bene!

how (that) sings well

'How she sings well!'

(iib) Come canta? (Answer: Bene.)

how sings

'How does she sing?'

However, the exclamative and interrogative differ in that the exclamative may contain a modifier in the predicate, here brava or bene in (ii), which is not present in the corresponding interrogative. (The interrogatives may marginally contain this extra modifier, but this gives rise to an interpretation for come different from that in the exclamative: cf. How does she sing well? Answer: By taking steroids.) This raises an issue concerning the syntactic analysis of the exclamatives, in particular the relationship between come and the constituent it seems to modify. Radford (1997) concludes that the two do not form a unit at any level. However, this leaves unexplained the relationship with the corresponding intcrrogatives, where come might be thought to have moved from the position of brava/bene. Notice as well that (iia) is plausibly also treated as a yes/no exclamative, that is one used to exclaim about the proposition that she sings well (as opposed to not singing well), in addition to its reading as a WH exclamative. Furthermore, we note that French has two lexical items corresponding to come: comme, which is possible only in exclamatives, and comment, used only in interrogatives. For these reasons, it is best to put come aside for the time being. 
a. $\quad *$ Cosa, a tua sorella, (che) le hanno regalato!

what to your sister that her have given

3. Finally, WH phrases formed with che+N are an intermediate case. Like the elements in (70)-(73), they may occur in both exclamatives and interrogatives, but unlike them they allow the complementizer. A left-dislocated element is also possible:
a. Che libri (che) ha comprato!
which books that has bought
'What books s/he bought!'
b. Che libri, a tua sorella, (che) le hanno regalato!
what books to your sister that her have given
'What books they gave your sister!'

We'll treat this type of WH phrases as ambiguous between the two classes of WH phrases. This explains their range of properties and will receive further support below.

We refer to the WH phrases that only occur in exclamatives as 'E-only' WH phrases (cf. (66)-(67)). In what follows, we will discuss the question of why E-only WH phrases, but not the others in (70)-(73), have the two syntactic properties mentioned above: cooccurrence with the complementizer and with a left-dislocated element to their right.

Before we move on, it is important to make clear the connection between the presence of an E-only WH phrase and the status of a clause as an exclamative. While the presence of an E-only phrase forces the clause to be exclamative, exclamatives can also be formed with other WH phrases (cf. (70)-(73)). This also makes the point that exclamatives cannot be defined by the cooccurence of complementizer che with a WH phrase. While all such cases are exclamative, there are other types of exclamative as well. A general account of this clause type must encompass all varieties.

\subsubsection{The internal structure of WH phrases: some technical issues}

Over the next two subsections we will present an argument that E-only WH phrases contain an element, a morpheme glossed as 'E-only', which is not shared by those WH phrases that can occur in interrogatives. This element requires the presence of the factive operator, explaining why such WH phrases only occur in exclamatives. We will show how their syntactic representation explains the facts noted in section 6.1.1: they must cooccur with the complementizer che and they allow a left-dislocated constituent to their right. In contrast, other WH phrases may or may not cooccur with the factive operator, and they receive a less highly-articulated syntactic structure which results in their incompatibility with a following complementizer and left-dislocated constituent.

The possibility or impossibility of having the E-only morpheme in a given WH phrase depends on the phrase's morphological makeup. Hence, our first step is a detailed investigation of the internal structure of the WH phrases. With regard to the issues we are concerned with here, the internal makeup of WH phrases in English is particularly transparent. Consider how many books, a case where three different components are explicitly and separately realized. The morpheme how indicates that we have WH quantification. Many provides a specification of the 'measure' by which the 
WH element quantifies, indicating that we are counting numbers of individuals. ${ }^{34}$ Books provides the sortal, indicating that these individuals are books.

$$
\begin{aligned}
& \text { how many books } \\
& \text { WH MEASURE SORTAL }
\end{aligned}
$$

$$
\begin{array}{lll}
\text { qu-anti } & \text { libri } & \text { (Italian) } \\
\text { WH+MEASURE } & \text { SORTAL } &
\end{array}
$$

Notice that many in this case is playing a different semantic role from that in He bought many books, since it does not indicate a large number, but merely the fact that some number is being asked for. The Italian counterpart of how many books is quanti libri, where quanti expresses both WH quantification (qu-) and measure (-ant-), along with agreement (-i).

The E-only counterparts of how many and quanti are how very many and che tanti, respectively. The English form suggests that the obligatory exclamative nature of these phrases is marked by an additional element, lexicalized as very in English, which modifies the specification of measure: ${ }^{35}$

$$
\begin{array}{lll}
\text { how very } & \text { many } & \text { books } \\
\text { WH E-ONLY } & \text { MEASURE } & \text { SORTAL }
\end{array}
$$

In Italian, we propose that the role of very in marking the E-only nature of the WH phrase is filled by tanti ('much/many'). More specifically, tanti should be viewed as a combination of $t$ - and -ant-, where -ant-is the same morpheme occurring in quanti and indicates measure. The morpheme $t$-corresponds to very in (79):

$$
\begin{array}{lll}
\text { che } & \text { t-anti } & \text { libri } \\
\text { WH } & \text { E-ONLY+MEASURE SORTAL }
\end{array}
$$

As we'll see, for morphological reasons the E-only marker only occurs in Italian when the WH element is che.

Recall that, when che is followed by an NP, it has two syntactic analyses, as an Eonly WH phrase and as a non-E-only WH phrase. We propose that the E-only form

${ }^{34}$ In fact, we are probably collapsing two concepts here: we are measuring an amount and computing this amount relative the count domain of individuals. In a case like how much milk, we continue to measure amount, but we compute the amount relative to a measure appropriate to the mass domain, like liters.

35 Of course very, like the corresponding Italian element tanti, can occur in non-exclamative constructions where no E-only morpheme would play a role. It is only in the presence of how or che, respectively, that these elements indicate the exclamative nature of the phrasc. It could be that very and tanti are ambiguous between E-only markers, which occur in these constructions, and ordinary modifiers. One point in favor of such an approach is the fact that not even nearly synonymous words can have the function of marking the phrase as E-only: ??how extremely tall, *what some book (cf. what a book), and *che molto alto ('how very tall'). Alternatively, there may be a single form of each, one whose potential to function as an E-only element is only triggered in the right syntactic context. Note that nothing can intervene between the WH word and these E-only markers: *how not very tall, *what many an enjoyable evening, *che cosi tanti libri ('how so many books'). This shows that the syntax of these cases is somehow special. 
contains a null morpheme, indicated by $\epsilon$, which represents the fact that the phrase is $\mathrm{E}$ only:

$$
\begin{aligned}
& \text { che } E \text { libri (... che ha comprato!) } \\
& \text { WH E-ONLY SORTAL that has bought }
\end{aligned}
$$

This case has a different interpretation from che tanti libri. Because the latter contains -anti, which indicates MEASURE, it exclaims over the number of individual books. In contrast, (81), which does not contain a MEASURE, has to do with some quality of the books. Thus, it means 'what books'.

The non-E-only WH form of che libri has the following structure:

$$
\begin{array}{ll}
\text { che } & \text { libri } \\
\text { WH } & \text { SORTAL }
\end{array}
$$

(82) occurs in both exclamatives and interrogatives, making the point that the E-only morpheme is not required to make a clause exclamative. This phrase lacks a specification of MEASURE, and so do not quantify over quantity or amount. Rather, it simply quantifies over books. This is particularly clear in the interrogative use, where it simply means 'which books'; in exclamatives, it means 'what books' like (81).

WH phrases containing che plus an adjective or adverb are similar but not identical to those containing nouns. They may or may not contain tanti, but in either case are Eonly forms. They have a structure parallel to (81), as seen below:

$$
\begin{array}{ll}
\text { che } \operatorname{tanto} / \epsilon+\varnothing & \text { alto } \\
\text { WH E-ONLY+MEASURE } & \text { SORTAL }
\end{array}
$$

As with (80), tanto represents both the E-only morpheme and measure. The element indicated with $\varnothing$ is simply a null version of -ant, the measure component of tanto/quanto. $\varnothing$, like -ant, is a bound morpheme, and must be combined with $\in$ to yield a null version of tanto. Tanto or this null counterpart must be present because WH phrases headed by an adjective or adverb must always contain a specification of measure. The reason for this is simply that these WH phrases always quantify over an amount or quantity (in the formal semantic literature on adjectives, these are often referred to as degrees). For instance, when we talk about height, we are always concerned with the degree of height; there is no meaning parallel to (82), something like 'what tall (thing)', lacking MEASURE.

Given that a specification of measure must be present, and that this goes along with the E-only morpheme as part of tanto/ $\epsilon+\varnothing$, che+ADJ/ADV cannot receive an interrogative interpretation comparable to (82). Interrogative WH phrases headed by an adjective or adverb always contain quanto, which as mentioned above marks measure with -ant-:

$$
\begin{array}{ll}
\text { qu-anto } & \text { alto } \\
\text { WH+MEASURE } & \text { SORTAL }
\end{array}
$$

The cases so far discussed contrast with the non-E-only WH phrases chi, cosa, and (less clearly) quanto+AP/ADVP/NP. We suggest that chi and cosa are not E-only WH phrases because they cannot incorporate the E-only morpheme. Specifically, none of the 
markers of E-only status (tanto, its null counterpart, or $\epsilon$ ) can $t$ within the already morphologically complex word. For example, chi is essentially the combination of WH (ch-) and the sortal HUMAN. Because this combination is lexicalized, it is impossible to insert material between $\mathrm{WH}$ and the sortal. A similar explanation may be given for the forms introduced by quanto. Quanto lexicalizes both the WH and measure components of the WH phrase, and so it is impossible to introduce an E-only marker in the appropriate position.

\subsubsection{The relation between the $W H$ phrase and the layers of $C P$}

Having analyzed in some detail the structure of WH phrases, we can now provide an account of the pattern outlined in section 6.1.1. There we observed that, in Italian, Eonly WH phrases obligatorily co-occur with the complementizer che and allow a leftdislocated constituent to their right. In non-E-only WH phrases, we find the same behavior as in interrogatives, namely the verb immediately following the WH phrase (in $\mathrm{C}^{0}$, we assume) and no following left-dislocated element. In this section we will connect the presence or absence of the E-only marker in the WH phrase to these properties. Moreover, with regard to non-E-only WH phrases, we will differentiate in structural terms those cases in which they occur in interrogatives from those in which they occur in exclamatives.

Our approach to this contrast builds on the proposal, discussed earlier, that exclamative clauses contain more structure in the CP domain than interrogatives. Moreover, we must incorporate the factive operator present in exclamatives but not interrogatives. In Watanabe's analysis, FACT was licensed by the higher predicate; this raises the question of what licenses it in exclamatives. Given that all exclamatives contain a WH operator, it is natural to suggest that this is the licenser. ${ }^{36}$ Thus, we propose that FACT is always in a specifier position lower than the one where the WH phrase is located. This may be implemented either through a selection mechanism from the head whose specifier hosts the WH phrase or by postulating an interpretable feature on the factive operator which may be checked by the WH phrase. We may tie the presence of the factive operator to the need to place WH phrases in a higher position in exclamatives than in interrogatives. Since the factive operator occupies a specifier of $\mathrm{CP}$, the WH phrase in exclamatives must be in a higher specifier position than in interrogatives.

Though all exclamatives contain more structure than interrogatives, we propose that, within the class of exclamatives, E-only WH phrases occupy a higher position than their non-E-only counterparts. This we take to be the result of the E-only morpheme needing to be licensed in the specifier of a higher functional projection. Its being in a higher position makes room for a left-dislocated element in a lower specifier.

We may summarize these ideas with Table 1 . Both of the exclamative structures contain the factive operator, regardless of the type of WH phrase, while interrogatives do not. Thus, the $\mathrm{CP}$ structure of exclamatives is always richer than that of interrogatives. Moreover, E-only WH phrases occupy a higher CP layer than non-Eonly phrases, even when the latter occur in exclamatives; this makes room for a leftdislocated element in the former case alone.

36 This proposal may also allow an explanation for the fact, noted by Emonds (1985) and discussed in Obenauer (1994), that pied-piping is more restricted in exclamatives than in interrogatives (cf. *With how many languages she is familiar! vs. With how many languages is she familiar?). If the WH phrase is too deeply embedded in the moved constituent, perhaps it cannot license the factive operator. 


\begin{tabular}{|l|l|l|ll|}
\hline & spec, $\mathrm{CP}^{3}$ & spec, $\mathrm{CP}^{2}$ & spec, $\mathrm{CP}^{1}$ & \multicolumn{1}{c|}{$\mathrm{C}^{0}$} \\
\hline Exclamative & E-only WH & FACT & (Left-dislocation) & che \\
\hline Exclamative & & non-E-only WH & FACT & V \\
\hline Interrogative & & & non-E-only WH & V \\
\hline
\end{tabular}

Table 1: Distribution of elements in Italian WH constructions

The next issue is why the complementizer is present with E-only WH phrases, while the verb is in $\mathrm{C}$ with the others. The generalization that emerges is that it is filled by the verb when spec, $\mathrm{CP}^{1}$ is occupied by an operator, whether FACT or WH. This amounts to extending to the factive operator the intuition that a WH operator must enter into a relation with the verb or a feature on inflection realized on the verb. If spec, $\mathrm{CP}^{1}$ does not contain an operator, its head is occupied by the complementizer che. We see the complementizer in exclamatives as a way to fill the $C^{0}$ position when verb movement has not been triggered by the presence of an operator.

A side issue that arises at this point is why an analysis allowing verb movement is not possible with E-only WH phrases. Specifically, what would be wrong with having $\mathrm{FACT}$ in spec, $\mathrm{CP}$, thereby triggering inversion? Assuming that the highest $\mathrm{C}^{0}$ requires the presence of $\mathrm{CP}^{2}$, there are two cases to consider. The first is that a left-dislocated element is in the specifier of $\mathrm{CP}^{2}$. This phrase would intervene between the WH phrase and factive operator, blocking the licensing of the latter. The second possibility is that nothing is in the specifier of $\mathrm{CP}^{2}$; but then both the specifier and the head would be empty, and this might be ruled out by a general principle that every phrase requires suitable 'lexical support'.

Turning now to Paduan, it differs from Italian in that the complementizer che may occur with non-E-only WH phrases, in addition to E-only ones as in Italian. For example:
a.
Chi che 1 ga fato inrabiare!
(Paduan)
who that s.cl has made to get angry
'The people he made angry!'
b. Cossa che l magnava!
what that s.cl ate
'What things he ate!'

We analyze this as showing that only WH operators trigger verb movement in Paduan; FACT in spec, $\mathrm{CP}^{\mathrm{i}}$ cooccurs with the complementizer, just as a left-dislocated element does. Otherwise matters are the same as in Italian. This is summarized in Table 2. ${ }^{37}$

\begin{tabular}{|l|l|l|ll|}
\hline & spec, $\mathrm{CP}^{3}$ & spec, $\mathrm{CP}^{2}$ & spec, $\mathrm{CP}^{1}$ & $\mathrm{C}^{0}$ \\
\hline Exclamative & E-only WH & FACT & (Left-dislocation) & che \\
\hline Exclamative & & non-E-only WH & FACT & che \\
\hline Interrogative & & & non-E-only WH & V \\
\hline
\end{tabular}

Table 2: Distribution of elements in Paduan WH constructions

${ }^{37}$ As seen in (51) above, non-E-only WH phrases may also cooccur with no+V in $\mathrm{C}^{0}$. This type of inversion is also possible in interrogatives with a particular pragmatic function (Portner \& Zanuttini 1996, 2000). Presumably this structure is possible in Italian as well, though it is impossible to see clear evidence for the inversion. Within the framework represented by Table 2 , no+ $\mathrm{V}$ would be licensed in $\mathrm{C}^{0}$ by either a WH or factive operator, just like simple inversion in Italian. 


\subsection{English}

English is like Italian and Paduan in that the set of WH phrases which can occur in exclamatives differs from that which can occur in interrogatives. This difference manifests itself in a rather different way, however. Some of the properties that distinguish E-only WH phrases in Italian don't play a role in English: an overt complementizer is never present, and left-dislocated elements may not follow the WH phrase. Instead, the two classes fundamentally differ in whether or not they occur in root clausal exclamatives at all. In this section, we will examine the nature of WH phrases in English exclamatives.

\subsubsection{Some properties of WH phrases in English}

1. Some WH phrases that occur in exclamatives do not occur in interrogatives. We continue to label them 'E-only WH phrases':

(86) a. What a nice guy he is! (cf. *What a nice guy is he?)

b. How very tall she is! (cf. *How very tall is she?)

2. All WH phrases that occur in interrogatives may also occur in embedded clausal exclamatives:

(87) a. It's amazing who/what/what book she saw.

b. It's amazing how tall she is.

c. It's amazing how quickly she reads.

However, not all WH phrases that occur in interrogatives also occur in root clausal exclamatives: $:^{38}$

(88) *Who/what/what book she saw! (cf. Who/what/what book did she see?)

(89) a. How tall she is! (cf. How tall is she?)

b. What books he reads! (cf. What books does he read?)

We will argue that, as with the corresponding cases in Italian, the WH phrases in (89) are ambiguous between E-only and non-E-only forms.

38 Elliott (1974) and Grimshaw (1977, 1979) point out the inability of simple WH words like who and what to occur in root clausal exclamatives. However, they point out that these WH words may occur in embedded exclamatives, as seen above. According to them, the fact that amazing does not embed a clause introduced by whether shows that it cannot take an interrogative complement. Hence, amazing has an exclamative complement in (87)a.

Lahiri (1991) disputes Elliott's and Grimshaw's conclusion. He takes the ungrammaticality (88) to show that who cannot introduce an exclamative clause, and thus concludes that the complement in (87)a is interrogative rather than exclamative. As will be shown in this section, we maintain the idea that (87)a embeds an exclamative. Lahiri also points out that amazing can take a multiple-WH complement, as in It is amazing which men love which women (Lahiri 1991: 26). He takes this as evidence that amazing can embed a interrogative, presumably because of the contrast with *What a nice man loves what a nice woman! From our perspective, what this shows is that E-only WH phrases cannot occur in multiple-WH structures, and while this is an interesting observation, it does not show that complements containing multiple WH phrases cannot be exclamative. 
3. There is another strategy for forming root exclamatives in English. These have the structure of a noun phrase with a relative clause: ${ }^{39}$

(90) a. The people who/that/ $\varnothing$ she would invite!

b. The things which/that/ $\varnothing$ he would do for his children!

c. The book which/that/ $\varnothing$ I saw!

These, in a sense, cover the territory of the cases which can't be expressed using a root clausal exclamative; for example, (90)a means what *Who she would invite! would mean, if it were grammatical. However, the distinction between E-only and non-E-only WH phrases is irrelevant here, since the WH words in nominal exclamatives are simply those otherwise available in relative clauses.

The pattern which needs to be explained is why certain WH phrases, the E-only ones, are able to occur in root clausal exclamatives, while others are not. As we did for Italian and Paduan, we will first examine the internal structure of the $\mathrm{WH}$ phrases, and then turn to their distribution.

\subsubsection{E-only and non-E-only WH phrases}

The clear cases of E-only WH phrases in English are how very many+NP, how very+AP/ADVP and what a+NP. Each case contains an element not present in the corresponding interrogative WH phrases, namely very and $a$; we propose that these represent the E-only nature of the phrase:
a.
how very
many
books
WH E-ONLY MEASURE
b.
how very
much
SORTAL
WH E-only
MEASURE
water
c.

how very $\varnothing$
SORTAL
tall
WH E-ONLY MEASURE SORTAL

The most straightforward cases are $(91) a-(91) b$, where each component of the phrase is overtly and separately expressed. In (91)c, we propose that measure is encoded by a null counterpart of much, parallel to the role of much in (91)b and tanto/ $\epsilon+\varnothing$ in (83). As mentioned in the discussion of Italian, the existence of an abstract element indicating measure is supported by the semantics of adjectives. Contemporary theories of the semantics of adjectives, in particular as they have developed in connection with the analysis of comparatives, claim that adjectives always contain a specification of degree, so that $S h e$ is tall is analyzed as 'she is $d$-much tall'. Empirical support comes from the fact that an overt instance of much may express degree in comparative exclamatives, as well as interrogatives:

(92) a. How very much taller (than him) she is!

b. How much taller (than him) is she?

In these cases, much expresses the degree-difference between the heights of the two individuals. ${ }^{40}$

39) These structures are mentioned by Elliott (1974: 243); Michaelis \& Lambrecht (1996) also include them within their class of exclamatives. 
Like the Italian che libri ('what books') in (81), English what a +NP exclaims over some quality of individuals and not their number. It therefore lacks a specification of measure.

$$
\begin{array}{ll}
\text { what a } & \text { guy } \\
\text { WH E-ONLY } & \text { SORTAL }
\end{array}
$$

It's natural to suppose that $a$ represents the phrase's E-only nature, since it is the extra element not present in interrogatives. ${ }^{4 i}$

Because they can occur in both interrogatives and root clausal exclamatives, we propose that what $+\mathrm{N}_{\mathrm{pl}}$ and how $\mathrm{A}$ are ambiguous between non-E-only and E-only analyses. As for what $+\mathrm{N}_{p l}$, it has two structures which, though identical in appearance, differ in terms of whether the determiner is present. The reason for this can be seen from a comparison with the corresponding singular forms. Recall that what $a+\mathrm{N}_{\mathrm{sg}}$ is $\mathrm{E}$ only, while what $+\mathrm{N}_{\mathrm{sg}}$ is not E-only. Given that the determiner for plural indefinite NPs in English is null, we may view the E-only form of what books as containing this empty determiner, the counterpart of a in (93). Thus, the exclamative form of what books is (94)a. In contrast, the interrogative version is simply (94)b, parallel to what book.
a. what $\emptyset_{\text {det }}$
books
b. What books
WH SORTAL

Turning now to how+A, the E-only analysis (95)a parallels Italian che alto (cf. (83)). The non-E-only analysis in (95)b is the counterpart of how very tall lacking the E-only marker very $(\mathrm{cf},(91) \mathrm{c}){ }^{42}$
a. how $\varnothing$
tall
WH E-ONLY+MEASURE SORTAL
b. how
$\varnothing$
tall
WH MEASURE SORTAL

\subsubsection{Nominal and clausal exclamatives}

Having examined the internal makeup of WH phrases in English, we can now turn to their distribution in exclamatives and interrogatives. The embedded cases, where all WH phrases can occur in exclamatives, is more parallel to Italian than the root one, where non-E-only WH phrases are impossible. However, even in embedded contexts

40 The sortal is the description of difference-degrees provided by the comparative clause, taller than him. The semantics of $(92) \mathrm{b}$ is roughly the following:

for-which $(d)[d$ is a degree of tallness \& $d$ ' is his degree of tallness \& $d$ " is her degree of tallness \& $d+d^{\prime}=d^{\prime \prime} 1$

4) In this paper we won't examine the details of phrase structure within complex WH phrases. See Corver (1990, Ch. 5) and Nelson (1997) for relevant discussion.

42 Italian che alto differs from English how tall because there is no overt or covert morpheme in Italian which expresses measure alone. Measure is always expressed in combination either with E-only (tanto) or with WH (quanto). This appears to be connected to the fact that measure is expressed in Italian APs via the bound morpheme -ant-, whereas in English it's expressed via the null counterpart of much (i.e. $d$-much). 
the languages differ in that in English a left-dislocated element may not follow the WH phrase:

$$
\text { *It's amazing what a nice book, to your sister, they gave her as a gift. }
$$

Thus, in English there is no evidence for a third level of CP structure like that postulated for Italian. We therefore place E-only and non-E-only WH phrases in the same position in embedded exclamatives, namely the specifier of $\mathrm{CP}^{2}$. This is summarized in Table 3.

\begin{tabular}{|l|l|ll|}
\hline & spec, $\mathrm{CP}^{2}$ & spec, $\mathrm{CP}^{\mathrm{l}}$ & $\mathrm{C}^{0}$ \\
\hline Exclamative & E-only WH & FACT & $\varnothing$ \\
\hline Exclamative & non-E-only WH & FACT & $\varnothing$ \\
\hline Interrogative & & non-E-only WH & V \\
\hline
\end{tabular}

Table 3: Distribution of elements in English embedded WH constructions

This analysis of embedded exclamatives leaves open why non-E-only WH phrases do not occur in root exclamatives. There is no fundamental incompatibility between these WH phrases and an exclamative interpretation, given that they are possible in embedded contexts. We thus take this to be a somewhat superficial difference between English and Italian. Within the perspective presented here, it is natural to suggest that this difference concerns the licensing of the factive operator. Specifically, we would say that English E-only WH phrases may license FACT, while non-E-only ones may not. In root exclamatives, then, we must have an E-only WH phrase. In embedded clauses, in contrast, the higher predicate is able to license FACT, just as in Watanabe's proposal for embedded factive declaratives. For this reason, embedded exclamatives are allowed regardless of the type of $\mathrm{WH}$ operator present, while root cases require an E-only WH phrase. $^{43}$

A remaining issue concerns the status of nominal exclamatives like those in (90). We have argued in Portner \& Zanuttini (forthcoming) that they are not simply ordinary noun phrases used for the function of exclaiming. In that paper wt argued that they also have the two syntactic components, which mark an exclamative, namely the WH and factive operators. As for the WH operator, the relative pronoun can fulfill this role. The factive operator is in the extra [spec, $\mathrm{CP}$ ] provided by an additional $\mathrm{CP}$ layer, as with clausal exclamatives. ${ }^{44}$ Thus, despite the differences between nominal and clausal

43. As observed in note 32, the data in Italian is in some respects similar to that in English. Root exclamatives with chi and cosa are less than perfect, unless they occur with a conditional verb form or negation. We don't treat their marginality in the same way as the English cases simply because we judge them to be grammatical, though difficult to interpret, in contrast to the English cases which are fully ungrammatical. Perhaps what is going on in Italian is that, because the word order is the same, it is difficult to distinguish root exclamatives introduced by chi or cosa from the corresponding interrogatives. Whencver we have a means of distinguishing the two, through the presence of an embedding predicate, negation, or non-indicative verb form, it becomes easier to observe the exclamative interpretation. In English, in contrast, the same kind of ambiguity does not arise, since subject-verb inversion clearly marks a root clause as interrogative.

44 Another alternative is that the definite article the marks the clause as, in effect, factive. The definite article triggers an existence presupposition: in the case of The people she would invite!, that there are people she would invite. This is equivalent to the factive presupposition required by the exclamative, namely that she would invite some people. If this is right, the definite article would fulfill the role of marking the phrase as lactive, and no other factive operator would be required. 
exclamatives, the two classes share the key syntactic components which make for an exclamative: a WH operator and a syntactic marker of factivity.

\subsection{Remarks}

In this section we have departed somewhat from the paper's main focus on the syntax/semantic interface, concentrating instead on the internal makeup of WH phrases. Our goal has been to relate the morphological properties of the WH phrase to certain syntactic properties of exclamatives and interrogatives. Not all WH phrases that occur in interrogatives also occur in exclamatives. In terms of our analysis, what differentiates an exclamative from an interrogative is the presence of a factive operator. Therefore, we see those $\mathrm{WH}$ phrases that only occur in exclamatives as requiring the presence of this factive operator.

While we have identified certain material, in particular tanto, very, and a (in how $v e r y+\mathrm{ADJ} / \mathrm{ADV}$ and what $a+\mathrm{N}$ ), as marking a phrase as E-only, we have not considered why these elements in particular are used. Are they arbitrary choices? On the one hand, the interpretations of tanto and very have a clear similarity to one component of the meaning of exclamatives, namely widening. It therefore might be suggested that they have the semantic role of marking widening, in addition to whatever syntactic role they might have. On the other hand, English a does not seem especially well-suited for this function, leaving open the possibility that the choice of E-only markers is indeed arbitrary.

Another issue is the nature of the relationship between E-only WH phrases and the factive operator. It may be that it is purely syntactic, so that FACT licenses the E-only element (even as the latter may also license the former). Alternatively, if E-only WH phrases mark widening, there may be some semantic relationship. Thus far, we have seen widening and factivity as two co-occurring but independent components of meaning in exclamatives, but perhaps widening only makes sense if the clause is factive. ${ }^{45}$ This remains to be further investigated.

\section{Conclusion}

In this paper we have investigated the characterization of exclamative clauses. Our main theoretical point has been that, despite their syntactic diversity, it is possible to give a uniform analysis which meets the definition of clause type as a pairing of form and function (Sadock \& Zwicky 1985). We have argued that the syntactic representation of exclamatives must realize their two central semantic properties: factivity and widening. Moreover, any clause which realizes these two components is an exclamative. In concrete terms, factivity is encoded through a factive operator of the sort discussed by e.g. Watanabe (1993), and widening depends on the presence of a WH operator. This way of looking at things implies that the category of exclamatives can only be understood at the interface, since the cooccurence of these two operators in the clause is only motivated by the semantic and pragmatic components.

45 Paduan has a clitic form of the negative marker no which contributes a meaning very similar to widening (cf. Portner \& Zanuttini 1996, 2000). It occurs both in exclamatives and (rhetorical) interrogatives. If this semantic function, which we have previously characterized as a conventional implicature, is in fact identical to widening, we cannot say that widening is necessarily tied to factivity. 
In addition, we have made a number of significant side contributions. First, we developed a number of descriptive criteria for identifying exclamative clauses (see also Portner \& Zanuttini 2000, Zanuttini \& Portner 2000). These make it possible to distinguish exclamative clauses from pragmatically similar declaratives and interrogatives. Given that exclamatives are often syntactically, as well as functionally, similar to interrogatives, it is especially important to be able to distinguish these two types. Our analysis allows us to understand the syntactic similarities and differences between these two types: they share the presence of a WH operator, reflecting their shared need to denote a set of alternative propositions, but differ in whether a representation of factivity is present. Second, we elaborated on the relationship between factivity and the syntactic structure in the CP-domain. Building on data and ideas from the literature, we propose that the extra structure present in exclamatives is needed to realize the factive operator in a way similar to embedded declarative factives. And third, we investigated the internal structure of the WH phrases that occur in exclamatives and interrogatives. This allowed us to better understand how the different components of WH phrases relate to one another and to other elements in the clause, including the factive operator, complementizer, and higher predicate.

While for the most part we have focused on clausal structures similar to WH interrogatives, our discussion has extended to other varieties of exclamatives. On the one hand, we have brought in yes/no exclamatives of the kind in (97). On the other, we have discussed English nominal exclamatives like (98).

$$
\begin{aligned}
& \text { No ga-lo magnà tuto! (Paduan) } \\
& \text { neg has-s.cl eaten everything } \\
& \text { 'He ate everything!' }
\end{aligned}
$$

The things he eats!

Despite their superficially different appearance from "core" cases of exclamatives, these represent the two components of exclamative meaning, and so fall within our uniform characterization.

Our study of exclamatives makes a contribution to the study of clause types in that it provides a rather different perspective on how clause types are marked. In much of the literature, one finds an identification of clause type with the syntactic expression of illocutionary force. One more minor point we have discussed is that illocutionary force is not the appropriate concept; sentential force is. More significantly, in the case of exclamatives there is not a single element which is present in all and only exclamatives. Thus, there is nothing to play the role of force-indicator. Instead, the clause type is marked by the cooccurence of markers of two defining semantic characteristics. This leaves open the question of whether sentential force is represented in the syntax at all. In some cases there is an element which could plausibly play the role of force indicator (e.g. very in English how very tall), but we do not have evidence that one is present throughout the range of cases. It is of course possible that force is syntactically represented, but the data we have are also compatible with the hypothesis that force is implemented in the semantic or pragmatic components, without needing any grammatical realization. More generally, our work shows that we must keep separate the questions of how force is indicated and how clause types are marked. Such a perspective might also be useful for the study of imperatives and interrogatives. For these types, an element in $\mathrm{C}$ has sometimes been cited as the force-indicator (e.g. Rivero 
1994, Rivero \& Terzi 1995, Han 1998). However, the re of this element, verb movement, is not uniformly present throughout the full range of cases. This casts doubt on the hypothesis that a force-indicating element is necessary because it functions as the marker of clause type. From the perspective of this paper, the relevant questions would not necessarily focus on force; rather, we would ask what semantic properties both uniquely identify each type and are represented in the syntax, thus creating the pairing of form and function which comprises a clause type. These properties might include force, but - as we see with the case of exclamatives - need not.

\section{References}

Austin, J. (1962): How to do Things with Words. New York: Oxford University Press.

Authier, J.-Marc P. (1992): Iterated CPs and embedded topicalization. Linguistic Inquiry 23:329-36.

Baker, C. L. (1970): Notes on the description of English questions: The role of an abstract question morpheme. Foundations of Language 6:197-219.

Benincà, Paola. (1996): La struttura della frase esclamativa alla luce del dialetto padovano. In Paola Benincà, Guglielmo Cinque, Tullio De Mauro, and Nigel Vincent (Eds.), Italiano $e$ dialetti nel tempo. Saggi di grammatica per Giulio C. Lepschy, 23-43. Roma: Bulzoni.

Benincà, Paola. to appear. Syntactic focus and intonational focus in the left periphery. In Guglielmo Cinque and Gianpaolo Salvi (Eds.), Current Studies in Italian Syntax Offered to Lorenzo Renzi.

Berman, Stephen R. (1991): On the Semantics and Logical Form of Wh-Clauses. PhD thesis, University of Massachusetts, Amherst.

Cheng, Lisa L.-S. (1991): On the typology of WH-questions. PhD thesis, MIT, Cambridge.

Chierchia, Gennaro and Sally McConnell-Ginet. (1990): Meaning and Grammar: An Introduction to Semantics. Cambridge, MA: MIT Press.

Cinque, Guglielmo. (1999): Adverbs and Functional Heads: A Cross-Linguistic Perspective. New York and Oxford: Oxford University Press.

Corver, Norbert. (1990): The syntax of left branch extractions. PhD thesis, Tilburg University.

Cresswell, Maxwell J. (1976): The semantics of degree. In Barbara Partee (Ed.), Montague Grammar. New York: Academic Press.

den Dikken, Marcel. (1992): Empty operator movement in Dutch imperatives. Language and Cognition 2:51-64.

Elliott, Dale E. (1974): Toward a grammar of exclamations. Foundations of Language 11:231246.

Emonds, Joseph E. (1985): A United Theory of Syntactic Categories. Dordrecht: Foris.

Gérard, J. (1980): L'exclamation en français . Tübingen: Niemeyer.

Graffi, Giorgio. (1996): Alcune ri sugli imperativi italiani. In Paola Benincà, Guglielmo Cinque, Tullio De Mauro, and Nigel Vincent (Eds.), Italiano e dialetti nel tempo. Studi di grammatica per Giulio Lepschy, 143-148. Roma: Bulzoni.

Grimshaw, Jane. (1977): English Wh-Constructions and the Theory of Grammar. PhD thesis, University of Massachusetts. Amherst.

Grimshaw, Jane. (1979): Complement selection and the lexicon. Linguistic Inquiry 10(2):279326.

Groenendijk, J. and M. Stokhof. (1984): On the semantics of questions and the pragmatics of answers. In F. Landman and F. Veltman (Eds.), Varieties of Formal Semantics. Dordrecht: Foris.

Hamblin, C.L. (1973): Questions in Montague English. Foundations of Language 10:41-53.

Han, Chung-Hye. (1998): The structure and interpretation of imperatives: mood and force in Universal Grammar. PhD thesis, University of Pennsylvania. 
Henry, Alison. (1995): Dialectal variation and Parameter Setting. New York and Oxford: Oxford University Press.

Henry, Alison. (1996): Imperative inversion in Belfast English. In James R. Black and Virginia Motapanyane (Eds.), Microparametric Syntax and Dialectal Variation, 79-93. Amsterdam/Philadelphia: John Benjamins.

Hoeksema, Jacob. (1983): Negative polarity and the comparative. NLLT 1:403-434.

Iatridou, Sabine and Anthony Kroch. (1992): The licensing of CP-recursion and its relevance to the Germanic verb-second phenomenon. Working Papers in Scandinavian Syntax 50:1-24.

Kadmon, Nirit and Fred Landman. (1993): Any. Linguistics and Philosophy 16:353-422.

Karttunen, Lauri. (1973): Presuppositions of compound sentences. Linguistic Inquiry 4:169-93.

Karttunen, Lauri. (1977): Syntax and semantics of questions. Linguistics and Philosophy 1:3-44.

Katz, Jerrold Jacob and Paul M. Postal. (1964): An Integrated Theory of Linguistic Descriptions. Cambridge, Mass.: MIT Press.

Kayne, Richard S. (1994): The Antisymmetry of Syntax. Vol. 25 of Linguistic Inquiry Monographs. Cambridge, Mass.: MIT Press.

Kennedy, Christopher. (1997): Projecting the adjective: The syntax and semantics of gradability and comparison. PhD thesis, University of California, Santa Cruz.

Kiparsky, Paul and C. Kiparsky. (1970): Fact. In M. Bierwisch and K. Heidolph (Eds.), Progress in Linguistics, 143-73. The Hague: Mouton de Gruyter.

Koster, Jan. (1994): Predicate incorporation and the word order of Dutch. In G. Cinque, J. Koster, J.-Y. Pollock, L. Rizzi, and R. Zanuttini (Eds.), Paths towards Universal Grammar. Studies in Honor of Richard S. Kayne, 255-276. Washington, D.C.: Georgetown University Press.

Lahiri, Utpal. (1991): Embedded Interrogatives and Predicates that Embed Them. PhD thesis, Massachusetts Institute of Technology.

Lewis, David K. (1979): A problem about permission. In E. Saarinen, R. Hilpinen, I. Niiniluoto, and M. Provence Hintikka (Eds.), Essays in Honour of Jaakko Hintikka, 163-175. Dordrecht: Reidel.

McCawley, Noriko. (1973): Boy! Is syntax easy! In C. Corum, T. Cedric Smith-Stark, and Ann Weiser (Eds.), Papers from the Ninth Regional Meeting of the Chicago Linguistic Society, 369- 377. Chicago Linguistics Society, The Univ. of Chicago.

Michaelis, Laura A. and Knud Lambrecht. (1996): Toward a construction-based theory of language function: The case of nominal extraposition. Language 72(2):215-47.

Milner, Jean-Claude. (1978): De la syntaxe à l'interprétation. Paris: Le Seuil.

Nelson, N. (1997): The structure of exclamatives: An extension of Kayne's (1997) analysis of sentential negation. ms., Rutgers.

Obenauer, Hans-Georg. (1994): Aspects de la syntaxe A-barre: Eets d'intervention et mouvements des quantifeurs. PhD thesis, Universit• e de Paris VIII.

Platzack, Christer and Inger Rosengren. (1994): On the subject of imperatives. A minimalist account of the imperative pronoun and negated imperatives. Sprache und Pragmatik 34:2667.

Pollock, Jean-Yves. (1989): Verb movement, Universal Grammar and the structure of IP. Linguistic Inquiry 20(3):365-424.

Portner, Paul and Raffaella Zanuttini. (1996): The syntax and semantics of scalar negation: Evidence from Paduan. In Kiyomi Kusumoto (Ed.), Proceedings of NELS XXVI, 257-271. GLSA, Univ. of Massachusetts.

Portner, Paul and Raffaella Zanuttini. 2000): The force of negation in Wh exclamatives and interrogatives. In L. Horn and Y. Kato (Eds.), Studies in Negation and Polarity: Syntactic and Semantic Perspectives, 201-39. New York and Oxford: Oxford University Press.

Radford, Andrew. (1982): The syntax of verbal WH-exclamatives in Italian. In Nigel Vincent and Martin Harris (Eds.), Studies in the Romance Verb, 185-204. London: Croom Helm.

Radford, Andrew. (1997): Per un'analisi delle frasi esclamative in italiano. In Lorenzo Renzi and M. A. Cortelazzo (Eds.), La Lingua Italiana fuori d'Italia, 93-123. Roma: Bulzoni. 
Rigamonti, A. (1981): Syntassi e semantica delle esclamative frasali complete in italiano. Mémoire di Licenza di italiano, Università di Ginevra.

Rivero, María Luisa. (1994): Negation, imperatives and Wackernagel effects. Rivista di Linguistica 6(1):39-66. Liliane Haegeman, guest editor.

Rivero, María Luisa and Arhonto Terzi. (1995): Imperatives, V-movement and logical mood. Journal of Linguistics 31:301-332.

Rizzi, Luigi. (1982): Issues in Italian Syntax. Dordrecht: Foris.

Rizzi, Luigi. (1996): Residual Verb Second and the Wh-criterion. In Adriana Belletti and Luigi Rizzi (Eds.), Parameters and Functional Heads. Essays in Comparative Syntax, 63-90. New York and Oxford: Oxford University Press.

Rizzi, Luigi. (1997): The ne structure of the left periphery. In Liliane Haegeman (Ed.), Elements of Grammar: Handbook of Generative Syntax. Dordrecht: Kluwer Academic Publishers.

Rochemont, Michael S. and Peter W. Culicover. (1990): English focus constructions and the theory of grammar. Cambridge: Cambridge University Press.

Rooryck, Johan. (1992): Romance enclitic ordering and Universal Grammar. The Linguistic Review 9(3):219-250.

Rullmann, Hotze. (1995): Maximality in the Semantics of WH-Constructions. PhD thesis, University of Massachusetts, Amherst.

Russell, Bertrand. (1905): On denoting. Mind 14:479-493.

Sadock, Jerrold M. (1971): Queclaratives. In Papers from the Seventh Regional Meeting of the Chicago Linguistic Society, 223-231. Chicago Linguistic Society.

Sadock, Jerrold M. and Arnold Zwicky. (1985): Speech act distinctions in syntax. In Timothy Shopen (Ed.), Language Typology and Syntactic Description, 155-196. Cambridge: Cambridge University Press.

Searle, John. (1965): What is a speech act? In M. Black (Ed.), Philosophy in America, 221-239. Unwin Hyman.

von Stechow, Arnim. (1984): Comparing semantic theories of comparison. Journal of Semantics 3:1-77.

Watanabe, Akira. (1993): Larsonian CP recursion, factive complements, and selection. In Amy J. Schafer (Ed.), Proceedings of NELS XXIII, 523-537. GLSA, Univ. of Massachusetts.

Wechsler, S. (1989): Verb second and illocutionary force. In K. Leel and D. Bouchard (Eds.), Views on Phrase Structure, 177-91. Dordrecht: Kluwer.

Zanuttini, Raffaella and Paul Portner. 2000): The characterization of exclamative clauses in Paduan. Language 76(1):123-32. 